\title{
Differential Mechanisms of Action and Efficacy of Vitamin E Components in Antioxidant Cytoprotection of Human Retinal Pigment Epithelium
}

\author{
R. Scott Duncan ${ }^{1}$, Daniel T. Hurtado ${ }^{2}$, Conner W. Hall ${ }^{1}$ and Peter Koulen ${ }^{1,2 *}$ \\ ${ }^{1}$ Vision Research Center, Department of Ophthalmology, School of Medicine, University of Missouri-Kansas City, Kansas City, \\ MO, United States, ${ }^{2}$ Department of Biomedical Sciences, School of Medicine, University of Missouri-Kansas City, Kansas City, \\ MO, United States
}

OPEN ACCESS

Edited by:

Kyriaki Thermos,

University of Crete, Greece

Reviewed by:

Rosario Amato,

University of Pisa, Italy Mohammad Shamsul Ola,

King Saud University, Saudi Arabia

*Correspondence:

Peter Koulen

koulenp@umkc.edu

Specialty section:

This article was submitted to Experimental Pharmacology and Drug

Discovery,

a section of the journal

Frontiers in Pharmacology

Received: 20 October 2021 Accepted: 17 November 2021

Published: 04 January 2022

Citation:

Duncan RS, Hurtado DT, Hall CW and Koulen P (2022) Differential Mechanisms of Action and Efficacy of Vitamin E Components in Antioxidant

Cytoprotection of Human Retinal

Pigment Epithelium.

Front. Pharmacol. 12:798938.

doi: 10.3389/fphar.2021.798938
The purpose of this study was to determine if different vitamin E components exhibit similar efficacy and mechanism of action in protecting Retinal pigment epithelium (RPE) cells from oxidative damage. We hypothesized that $\alpha$-tocopherol $(\alpha T)$ is unique among vitamin $E$ components in its cytoprotective mechanism of action against oxidative stress in RPE cells and that it requires protein synthesis for optimal antioxidant effect. We used cell viability assays, fluorescent chemical labeling of DNA and actin and immuno-labeling of the antioxidant proteins $\mathrm{Nrf} 2$ and Sod2 and of the tight junction protein, $\mathrm{ZO}-1$, and confocal microscopy to determine the effects of $\alpha \top$ and $\gamma \top$ against oxidative stress in immortalized human RPE cells (hTERT-RPE). Using the four main vitamin E components, $\alpha T, \gamma \top, \delta$-tocopherol $(\delta T)$ and $\alpha$-tocotrienol $(\alpha \operatorname{Tr})$, we ascertained that they exhibit similar, but not identical, antioxidant activity as aT when used at equimolar concentrations. In addition, we determined that the exposure time of RPE cells to $a$-tocopherol is critical for its ability to protect against oxidative damage. Lastly, we determined that $\alpha \mathrm{T}$, but not $\gamma \mathrm{T}$, partially requires the synthesis of new proteins within a 24-h period and prior to exposure to tBHP for optimal cytoprotection. We conclude that, unlike $\gamma \top$ and $\delta \mathrm{T}$, $\alpha \top$ appears to be unique in its requirement for transport and/or signaling for it to be an effective antioxidant. As a result, more focus should be paid to which vitamin E components are used for antioxidant interventions.

Keywords: retina, antioxidant, retinal pigment epithelium (RPE), age related macular degeneration (AMD), vitamin E, tocopherol, oxidative stress

\footnotetext{
Abbreviations: ANOVA, analysis of variance; $\alpha \mathrm{T}, \gamma \mathrm{T}, \delta \mathrm{T}$, alpha tocopherol, gamma tocopherol and delta tocopherol, respectively; $\alpha \mathrm{Tr}$, alpha tocotrienol; AMD, age-related macular degeneration; CHX, cycloheximide; DNA, deoxyribonucleic acid; DAPI, 4',6-diamidino-2-phenylindole; hTERT, human telomerase reverse transcriptase; Nrf2, nuclear factor erythroid 2related factor 2; RPE, retinal pigment epithelium; Sod2, superoxide dismutase 2; tBHP, tert-butyl hydroperoxide; VC, vehicle control; ZO-1, zona occludens.
} 


\section{INTRODUCTION}

Non-exudative or dry Age-Related Macular Degeneration (AMD), the most common form of AMD, is the leading cause of blindness in people over the age of 65 (Wong et al., 2014; Fleckenstein et al., 2021; Thomas et al., 2021). Dry AMD exhibits some genetic predisposition, but it is a multifactorial disease likely also requiring more than one therapeutic approach for treatment. Dry AMD pathophysiology includes Drusen deposition, oxidative stress, inflammation, geographic atrophy and, ultimately, vascular dysfunction (Hageman et al., 2001; Romero-Vazquez et al., 2021; Tisi et al., 2021; Toma et al., 2021). As a result, compounds that alter Drusen formation, reduce oxidative stress and inflammation, have the potential to prevent cellular loss and control of vascular changes can be potential therapeutic targets (Cabral de Guimaraes et al., 2021; Romero-Vazquez et al., 2021; Toma et al., 2021).

Oxidative stress is a major contributor to retinal pigment epithelium (RPE) dysfunction and cell death in dry AMD (Kunchithapautham et al., 2014; Marazita et al., 2016; Romero-Vazquez et al., 2021; Tisi et al., 2021; Toma et al., 2021). Common sources of oxidative stress in the retina include intrinsic factors such as mutations in complement factor genes, mitochondrial dysfunction and aging as well as extrinsic factors including excessive exposure to sunlight (blue light) and cigarette smoke (Hageman et al., 2001; Tomany et al., 2004; Edwards et al., 2005; Hageman et al., 2005; Khan et al., 2006; Seddon et al., 2006; Chakravarthy et al., 2007; Fletcher et al., 2008; He and Tombran-Tink, 2010; Kunchithapautham et al., 2014; Rohrer et al., 2016; Borras et al., 2019). Vitamin E has been studied as a potential therapy for diseases consisting of oxidative damage (Matsura, 2019; Cabral de Guimaraes et al., 2021). Vitamin E, and its constituent vitamers, exert at least some of their protective effects against oxidative stress through their direct free radical neutralizing effects, or as antioxidants. This is supported by extensive research over several decades (Sen et al., 2006; Traber and Atkinson, 2007; Zingg, 2019). More recently, however, it has become increasingly clear that tocopherols and tocotrienols can serve as signaling molecules to activate kinases and transcription factors alter gene expression (Chiricosta et al., 2019; Ghani et al., 2019; Gugliandolo et al., 2019; Mehrabi et al., 2019; Zingg, 2019; Hidalgo et al., 2020; Moore et al., 2020; Ding et al., 2021; Ungurianu et al., 2021; Willems et al., 2021).

The Age-Related Eye disease Study 1 (AREDS 1) clinical trial determined whether the oral delivery of nutritional supplements vitamin $A$, vitamin $C$, vitamin $E$, zinc and copper could improve outcomes in patients with wet and dry forms of AMD (AgeRelated Eye Disease Study Research Group, 2001; Sackett and Schenning, 2002; SanGiovanni et al., 2008; Pemp et al., 2010; Chew et al., 2013). These supplements appeared to slightly reduce the risk for progression to wet AMD in some patients, but they had no effect on dry AMD. A follow-up study, AREDS 2, added omega- 3 fatty acids and the carotenoids, lutein and zeaxanthin, but these additional compounds had no additional beneficial effect of patient outcomes compared to AREDS 1 (Age-Related Eye Disease Study 2 Research Group, 2013; Agrón et al., 2021).
Overall, the studies suggested that vitamin, zinc and carotenoid supplementation alone is not effective in combating AMD.

There were limitations to the study design that did not adequately address whether vitamin E can exhibit therapeutic potential. One of the major problems with the AREDS studies was that the route of administration was oral, meaning that the supplements were subjected to first-pass metabolism leading likely to insufficient amounts reaching the affected tissues, namely the RPE (Hensley et al., 2004; Azzi, 2018; Uchida et al., 2018). First-pass metabolism in the liver changes the composition of vitamin $\mathrm{E}$ vitamers from predominately $\gamma$-tocopherol $(\gamma \mathrm{T})$ and other forms to primarily a-tocopherol (aT) (Azzi, 2018; Uchida et al., 2018). No clinical trial to date has tested whether alternative routes of vitamin $\mathrm{E}$ administration can improve clinical outcomes in dry AMD patients. Lastly, studying multiple test compounds or drugs at the same time in a mixture, or cocktail, resulting in complex pharmacokinetics and/or pharmacodynamics remains extremely challenging. With regard to vitamin $\mathrm{E}$, it is reasonable to test individual tocopherols or tocotrienols or well-defined combinations thereof.

Vitamin E concentrations in blood serum has been determined in previous studies, but the concentrations in the retina obtained from normal dietary intake is not precisely known (Müller and Pallauf, 2003; Arigony et al., 2013; Azzi, 2018; Jamro et al., 2019; Zingg, 2019). Studies using animals such as rodents, canine and bovine sources indicate that the serum concentration of supplemented tocopherols, particularly $\alpha \mathrm{T}$, is in the low micromolar range (Müller and Pallauf, 2003; Jamro et al., 2019). As alluded to earlier, clinical studies utilizing vitamin $\mathrm{E}$ are difficult to interpret as $\gamma \mathrm{T}$ and $\delta \mathrm{T}$ and tocotrienols are metabolized rapidly leaving only elevated levels of At (Hosomi et al., 2019).

The central nervous system, including the retina, has a high oxygen demand and, therefore, has an elevated rate of respiration leading to increased generation of reactive oxygen species from mitochondria (Liu et al., 2006; Rohrer et al., 2016). Furthermore, blue light can cause free radical formation in photoreceptor outer segments possibly leading to oxidative stress (Dalvi et al., 2019; Zhang et al., 2019). Vitamin E can reduce of polyunsaturated fatty acid auto-oxidation in the membranes of photoreceptor outer segments (Robison et al., 1982).

This study, to our knowledge, is the first of its kind in determining the comparative kinetics and cytoprotective efficacy between $\alpha \mathrm{T}$ and $\gamma \mathrm{T}$ against oxidative damage, the effects of these tocopherols on the expression and subcellular localization of antioxidant and structural proteins, and the requirement for protein synthesis for these observed effects in RPE cells.

Here, we determined whether specific components of vitamin E exhibit unique cytoprotective properties in immortalized human RPE cells (hTERT-RPE cells). We used supraphysiological concentrations $(>25 \mu \mathrm{M})$ of $\gamma \mathrm{T}, \delta \mathrm{T}$ and $\alpha \mathrm{Tr}$ to ascertain whether they elicit similar cytoprotective effects as $\alpha \mathrm{T}$ (Azzi, 2018). In addition, we determined whether short-term (4h) versus longer-term (24-h) exposure to tocopherols results in a similar degree of cytoprotection against oxidative stress and cell death. 
As cell signaling events often lead to changes in gene expression, and subsequent protein expression, we also determined whether $\alpha \mathrm{T}$ and $\gamma \mathrm{T}$ affect the expression of the antioxidant proteins, nuclear factor erythroid 2-related factor 2 (Nrf2) and superoxide dismutase 2 (Sod2) and the structural proteins, actin and zona occludens (ZO-1). In addition, we determined whether exposure of hTERT-RPE cells to tocopherols requires the synthesis of new proteins within a 24-h period and prior to exposure to $\mathrm{BH}$ for cytoprotection. If synthesis of new proteins by tocopherol-mediated cellular signaling is required for some or all their cytoprotective effects, this will provide clearer evidence of the importance of the signaling function of tocopherols, in addition to their direct antioxidant function, and shed light on new potential therapeutic targets.

\section{MATERIALS AND METHODS}

\section{Cell Culture and Treatments}

Human telomerase reverse transcriptase-overexpressing RPE (hTERT-RPE) cells were provided by American Type Culture Collection (ATCC, \# CRL-4000) and were maintained according to ATCC instructions. In brief, cells were grown in DMEM:F12 (1:1) $+10 \% \mathrm{FBS}+10 \mu \mathrm{g} / \mathrm{ml}$ gentamicin to $>50 \%$ density before splitting for growth or to full confluence for use in experiments. Tocopherols were obtained from Sigma-Aldrich (Millipore-Sigma, Burlington, MA, United States). Tocopherols were diluted in cell culture-grade DMSO to a working stock solution concentration of $100 \mathrm{mM}$ and diluted in cell culture media to a final concentration of $100 \mu \mathrm{M}$. Tocopherol exposure times were either $4 \mathrm{~h}$ or $24 \mathrm{~h}$ prior to treatment with oxidant. Tert-butyl hydroperoxide (tBHP) (70\% dilution, Acros Organics, Antwerp, Belgium), the oxidant used in this study, was diluted in ultrapure water $\left(>18 \Omega \mathrm{ohm} \cdot \mathrm{ml}^{-1}\right)$ to a final working concentration of $100 \mathrm{mM}$. The tBHP was diluted in culture media to a final concentration of between $100-500 \mu \mathrm{M}$ for oxidative stress of cells. Cycloheximide (CHX) (Millipore Sigma, Burlington, MA, United States), used to inhibit protein synthesis, was diluted in PBS to a stock solution of $10 \mathrm{mM}$. CHX was diluted in media at a final concentration of $1 \mu \mathrm{M}$ (IC50 0.53 $\mu \mathrm{M})$ and applied to cell $1 \mathrm{~h}$ prior to addition of tocopherols. A vehicle control (VC) was used as a control for each chemical or compound treatment. Experiments were carried out in triplicate.

\section{Calcein-AM Assay and Cell Staining}

The calcein-AM assay was used to measure cellular esterase activity, a surrogate of cell viability. Calcein-AM dye (Invitrogen/Thermo Fisher Scientific, Waltham, MA, United States) was suspended in cell culture-grade DMSO to a final stock concentration of $2 \mathrm{mM}$ and diluted in media to final concentration of $2-5 \mu \mathrm{M}$. The assay was carried out in detail as described elsewhere (Duncan et al., 2007). In brief, cellular loading of calcein-AM was carried out in Dulbecco's PBS (Millipore Sigma) for $20 \mathrm{~min}$. Plates were read at $485 \mathrm{~nm} /$ $535 \mathrm{~nm}$ (excitation/emission) in a Flex Station three multi-mode plate reader (Molecular Devices). Detector sensitivity in plate reader assays was determined automatically by the instrument. Changes in calcein fluorescence in all experimental groups were compared to fluorescence values for the control groups.
An alternative measure of calcein fluorescence was conducted by observing calcein-AM dye-loaded cells from each condition under a fluorescence microscope. The camera exposure time settings were kept constant throughout image acquisition so that relative fluorescence intensities of cells and cellular morphology could be calculated from images. This approach was included to address high levels of calcein fluorescence in attached damaged cells that may give false positive readings in a plate reader assay.

For cell staining of fixed cells, nuclei were labeled with dilute $4^{\prime}, 6$ diamidine- $2^{\prime}$-phenylindole dihydrochloride (DAPI) stain (Millipore Sigma) and fluorescent dye $594 \mathrm{~nm}$-labeled phalloidin (phalloidin594; Abnova, Taipei City, Taiwan). Phalloidin labels only filamentous actin; non-filamentous, or globular, actin was not labeled. For DAPI and phalloidin labeling, cells were rinsed with DPBS and fixed for $20 \mathrm{~min}$ in $4 \%$ paraformaldehyde (PFA). After rinsing, PBS containing $0.5 \mu \mathrm{g} / \mathrm{ml}$ DAPI and 1:1,000 dilution of phalloidin-594 was added to cells followed by incubation for $2 \mathrm{~h}$. Cells were then rinsed three times with PBS and mounted onto glass slides with Aqua Polymount medium (Polysciences, Warrington, PA, United States).

\section{Immunocytochemistry}

Immunocytochemistry on treated cells was carried out as described elsewhere (Duncan et al., 2007). In brief, treated cells were rinsed with PBS, fixed with $4 \%$ paraformaldehyde for $20 \mathrm{~min}$ and then rinsed three times each for $5 \mathrm{~min}$. After blocking, antibodies were applied to fixed cells overnight at $4^{\circ} \mathrm{C}$. Antibodies used were mouse anti-Nrf2 (Abcam \#ab89443) at 1:200, mouse anti-ZO-1 (Invitrogen \#33-9100) at 1:200 and mouse anti-Sod2 (Invitrogen \#A21990) at 1:250. Alexafluor $^{\mathrm{TM}} 488$ - or Alexafluor ${ }^{\mathrm{TM}} 594$-conjugated goat anti-rabbit or mouse IgG secondary antibodies (Invitrogen) were used for fluorescent labeling of cells. Coverslips were mounted using Aqua Polymount medium (Polysciences).

\section{Microscopy}

Microscope images were acquired using a Leica TCS SP5-X white light laser scanning confocal microscope (Leica Microsystems, Mannheim, Germany) with fully motorized stage and CTR 6500 controller. DAPI and phalloidin labeling was detected using a diode laser $(405 \mathrm{~nm})$ with a detection range of $410-470 \mathrm{~nm}$ and tunable white light laser set at $590 \mathrm{~nm}$ excitation with a detection range of $600-650 \mathrm{~nm}$. All images were acquired using $40 \mathrm{X}$ or $63 \mathrm{X}$ oil objectives and images were saved as Leica LIF files for later analysis.

\section{Image Analysis}

Images were analyzed using Image-J FIJI software (open source, $\mathrm{NIH}$, Bethesda, MD, United States). Images were converted to maximum intensity projection images in eight- or 16-bit TIFF format. Images were thresholded to remove background fluorescence leaving signal specific for the protein of interest. Mean and maximum grey level (intensity), area, \% area and integrated density were calculated. Where necessary, histogram analyses were carried out to determine the counts at each pixel intensity. A cell counter tool in FIJI was used to manually count cell nuclei. To measure nuclear Nrf2 levels, colocalization analysis was conducted using the FIJI coloc2 tool. 

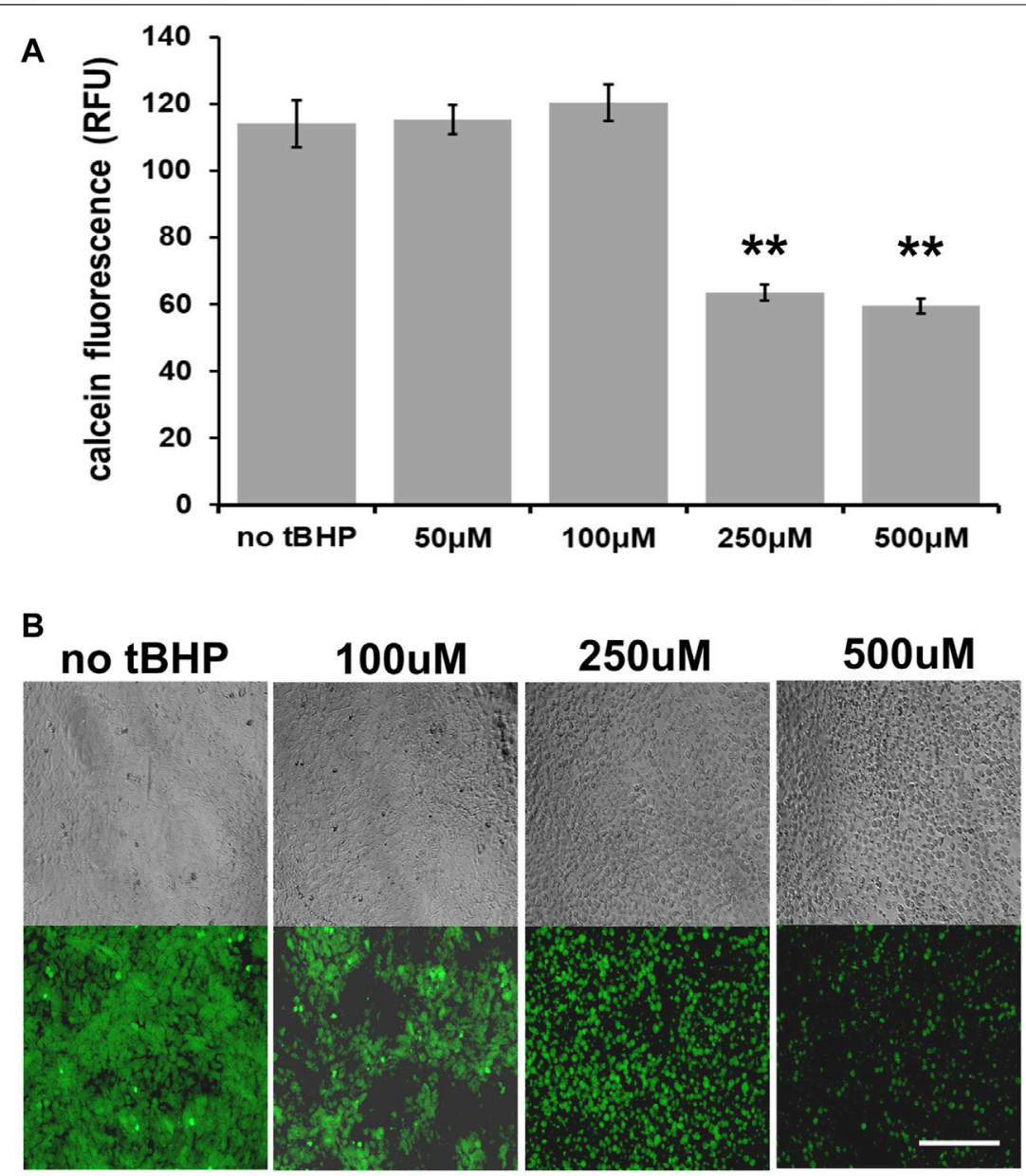

FIGURE 1 | Sensitivity of hTERT-RPE cells to tert-butyl hydroperoxide (tBHP). (A) Calcein assay results of hTERT-RPE) cells exposed to different concentrations of tBHP $(50,100,250$, and $500 \mu \mathrm{M}$ ) for $24 \mathrm{~h}$ to establish a kill curve. Exposure of cells to 250 and $500 \mu \mathrm{M} \mathrm{tBHP}$ led to 44 and $47 \%$ reduction in calcein fluorescence, respectively. Calcein-AM assay data are an average of eight samples. One-way analysis of variance (ANOVA) analysis was performed to determine differences between groups. ${ }^{* *} p=\leq 0.01$ versus VC-tBHP. (B) Microscopic images of calcein-stained tBHP-exposed hTERT-RPE cells visually showing the tBHP concentration response. Top panel row-representative phase contrast images; bottom panel row-representative calcein fluorescence $(488 \mathrm{~nm} / 530 \mathrm{~nm}$ excitation/emission) images. Scale bar is $100 \mu \mathrm{m}$.

\section{Statistics}

Statistical difference between more than two groups, which includes all of the data herein, was carried out using a one-way ANOVA with a post hoc Bonferroni correction using GraphPad Prism software (GraphPad, San Diego, CA, United States).

\section{RESULTS}

\section{Sensitivity of hTERT-RPE Cells to tBHP-Mediated Oxidative Stress Damage}

We first determined the optimal tBHP concentration to use for cytoprotection experiments. At confluence (100\% cell density), $100 \mu \mathrm{M}$ tBHP exhibits no noticeable loss of cell viability (as determined by a calcein fluorescence plate reader assay) while 250 and $500 \mu \mathrm{M}$ decreases viability by 44 and $47 \%$, respectively (Figure 1A). As a result, we used a high tBHP concentration of $500 \mu \mathrm{M}$ in this study to determine cytoprotection provided by vitamin E components. Although high concentrations of tBHP $(250-500 \mu \mathrm{M})$ reduced cellular esterase activity measured by calcein fluorescence, microscopic observation of calcein-AM loaded cells revealed that few cells became detached within $24 \mathrm{~h}$ after tBHP exposure and instead exhibited loss of cellular morphology, a common sign of cell death (Figure 1B) This microscopy approach allows a qualitative in addition to quantitative assessment of cell health unlike plate reader assays which offer only quantitative data.

\section{Cytoprotective Effects of the Main Vitamin E Components Against Oxidative Damage in hTERT-RPE Cells}

To determine if vitamin E components protect hTERT-RPE against severe (lethal) oxidative damage elicited by $500 \mu \mathrm{M}$ tBHP and help maintain cell viability, we exposed hTERT-RPE cells to vitamin E components $(\alpha \mathrm{T}, \gamma \mathrm{T}, \delta \mathrm{T}$ and $\alpha \mathrm{Tr}-100 \mu \mathrm{M}$ of 

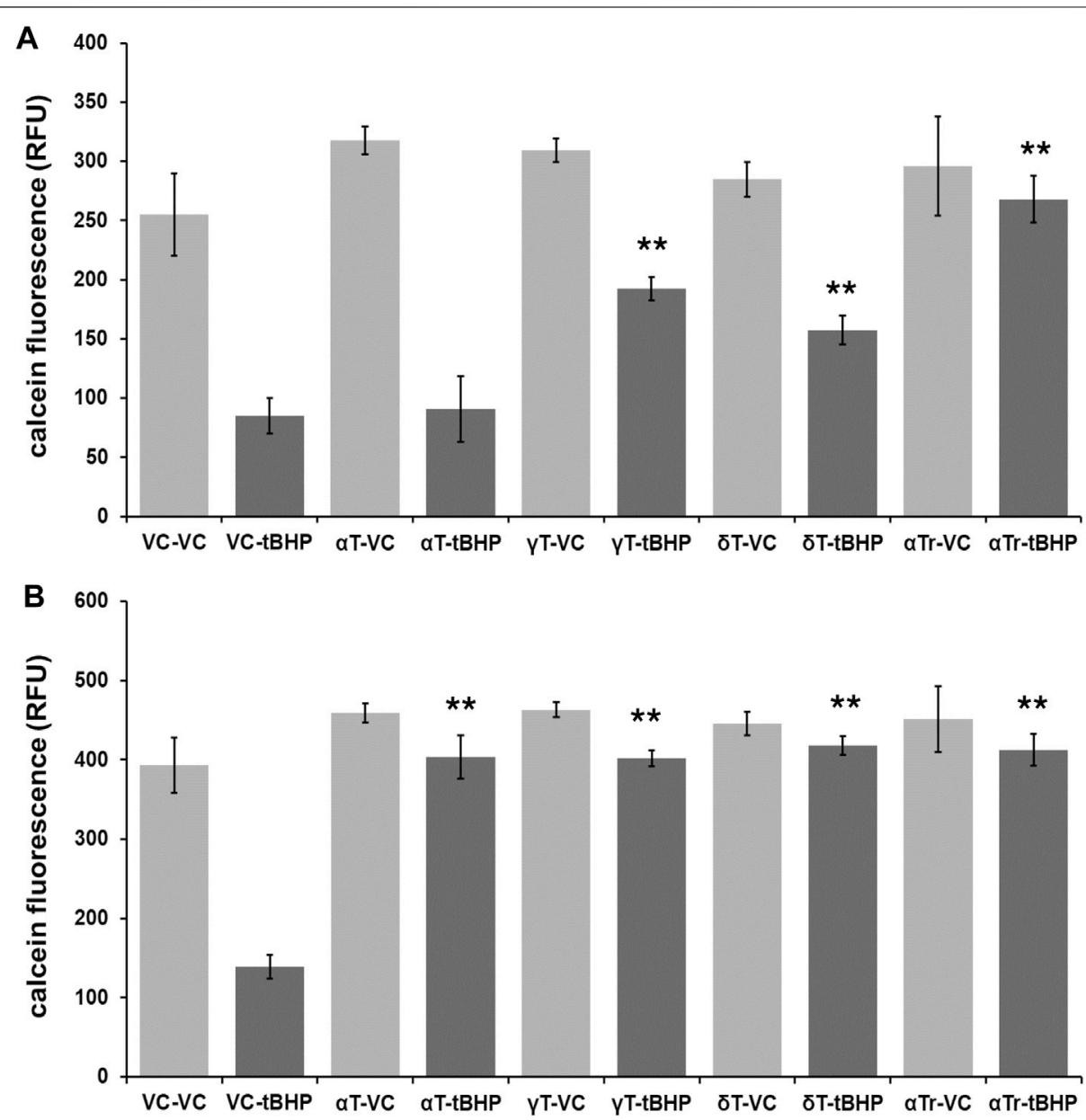

FIGURE 2 | Viability of RPE cells exposed to tocopherols and $\mathrm{aTr}$ for either four or $24 \mathrm{~h}$ followed by exposure to tBHP (500 $\mu \mathrm{M}$ ) for $24 \mathrm{~h}$ measured using the calceinacetomethoxy ester (AM) assay. (A) Calcein-AM assay results of hTERT-REP cells exposed to 4-h of vitamin E components or vehicle control (VC) followed by 24-h tBHP exposure. Light gray bars are conditions with no tBHP while dark gray bars are conditions with $500 \mu \mathrm{M} \mathrm{tBHP}$. The 4-h aT exposure offered no protection of hTERT-RPE cells against tBHP. (B) Calcein-AM assay results of hTERT-REP cells exposed to vitamin E components (or VC) for 24-h followed by 24-h tBHP exposure. Light gray bars are conditions with no tBHP while dark gray bars are conditions with $500 \mu \mathrm{M} \mathrm{tBHP}$. At $24 \mathrm{~h}$, all vitamin E components protected ( $\geq 85 \%$ protection) hTERT-RPE cells against tBHP. One-way ANOVA analysis with post hoc Bonferroni correction was performed to determine differences between groups. ${ }^{\star \star} p=\leq 0.01$ versus vehicle control (VC)-tBHP. Calcein assay data from each data set are from an average of four samples. Data for 4-h tocopherol and 24-h tocopherol groups were compared using a one-way ANOVA with Tukey's post hoc test to determine whether tocopherol protection was time-dependent.

each) for either four or $24 \mathrm{~h}$, washed cells and then exposed cells to tBHP $(500 \mu \mathrm{M})$ for an additional $24 \mathrm{~h}$. After the 24-h tBHP insult, we carried out a calcein assay to measure cell viability. None of the tocopherols ( $\alpha-, \gamma-$, and $\delta$ ) nor $\alpha \operatorname{Tr}$ exhibited any measurable toxicity at $100 \mu \mathrm{M}$ (Figure 2).

The shorter 4 -h tocopherol exposure time resulted in a differential degree of protection with $\gamma \mathrm{T}$ and $\delta \mathrm{T}$ and $\alpha \mathrm{Tr}$ offering some protection (60, 50, and 90\%, respectively) (Figure 2A). The 4-h a $\mathrm{T}$ exposure offered no protection against tBHP (Figure 2A). The longer 24-h tocopherol exposure time resulted $90 \%$ protection with all vitamers tested (Figure 2B). This suggests that the protective effect of $\alpha \mathrm{T}$ against oxidative stress is time-dependent, whereas the other vitamers are not.

After 24-h exposure to tBHP, cells remained largely attached to plate wells making the calcein assay limited in determining the percentage of non-viable cells. As a result, we use microscopic methods to measure loss of cellular morphology and nuclear shrinkage (pyknotic nuclei) as surrogate markers of apoptotic cell death.

\section{Effects of Tocopherols and $\alpha$-Tocotrienol on Actin Dynamics}

The actin cytoskeleton is critical for the maintenance of cell morphology, development and motility. Since cellular morphology is significantly affected by cell death, including apoptosis (Laster and Mackenzie, 1996; Levee et al., 1996), we labeled filamentous actin with fluorescently labeled phalloidin, which binds with high affinity to filamentous but not globular actin. This labeling allowed us to easily visualize changes in cell morphology that accompany cell death. 

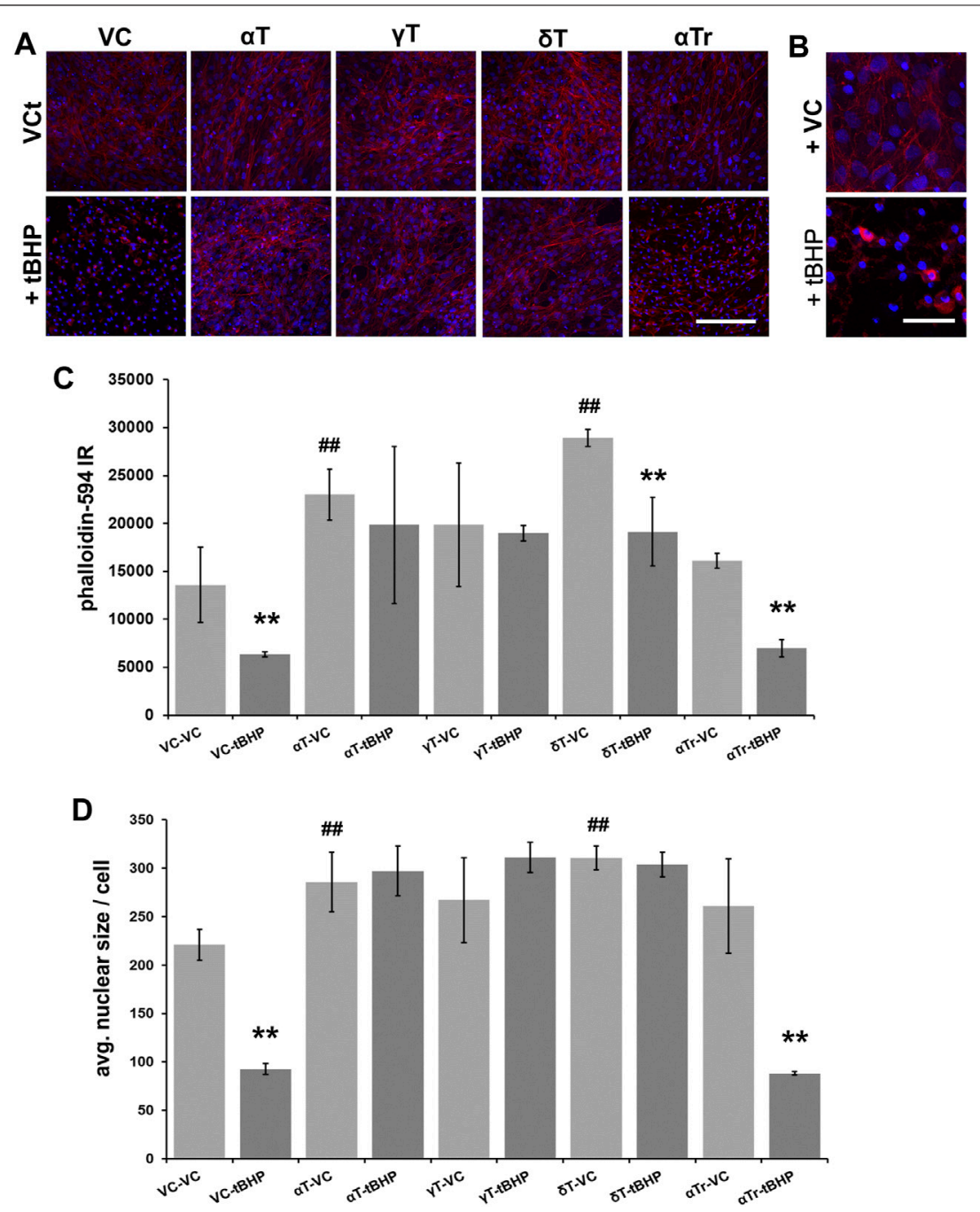

FIGURE 3 | Effect of 24-h aT, $\gamma$ T and $\delta T$ and $\alpha$ Tr exposure on RPE actin dynamics after subsequent tBHP-induced oxidative stress. RPE cells were exposed to a vehicle control (VC) $\alpha \mathrm{T}, \gamma$ T or $\delta \mathrm{T}$ or $\alpha \mathrm{Tr}$ for $24 \mathrm{~h}$ prior to tBHP. (A) tBHP reduced phalloidin fluorescence (red) and nuclear area (DAPI, blue fluorescence). A reduction in filamentous actin (phalloidin (red) fluorescence) is suggestive of actin destabilization observed in cell death resembling apoptosis. Nuclear size (blue) is reduced during cell death, particularly during apoptosis. Images were acquired at 40X magnification; scale bar is $100 \mu \mathrm{m}$. (B) A close up image of tBHP-mediated reduction in filamentous actin labeling by phalloidin and reduction in nucleus size caused by tBHP exposure. Scale bar is $25 \mu \mathrm{m}$. (C) Graphical data showing that exposure of cells to $\alpha \mathrm{T}$ and $\gamma \mathrm{T}$, and to a lesser extent $\delta \mathrm{T}$, prevented this effect in hTERT-RPE cells. $\alpha \mathrm{Tr}$, however, could not prevent the reduction of phalloidin staining and nuclear size. (D) Exposure of cells to $\alpha \mathrm{T}$ and $\delta \mathrm{T}$ led to an increase in nuclear size. Exposure of cells to tBHP led to a reduction in nucleus size indicative of pyknosis. The exposure of cells to $\alpha \mathrm{T}, \gamma \top$ and $\delta \mathrm{T}$ prevented the tBHP-mediated reduction in nuclear size, while exposure of cells to $\alpha \operatorname{Tr}$ did not. ${ }^{* *} p \leq 0.01$ with tBHP versus the same condition without tBHP; ${ }^{\# \#} p \leq 0.01$ with tocopherol versus without tocopherol. Microfluorimetric analyses are from an average of three images. One-way ANOVA analysis with post hoc Bonferroni correction was performed to determine differences between groups.

Pre-exposure of cells to $\alpha \mathrm{T}$ and $\delta \mathrm{T}(100 \mu \mathrm{M}$ of each) for $24 \mathrm{~h}$ increased phalloidin labeling of filamentous actin, suggesting that actin was stabilized by these tocopherols (Figure 3A). Gamma-tocopherol appeared to increase phalloidin-594 fluorescence, but it failed to reach statistical significance (Figures 3A,C). Pre-exposure of cells to $\gamma \mathrm{T}$ and $\delta \mathrm{T}$ prevented $\mathrm{tBHP}$-mediated actin destabilization, whereas aTr did not. Pre-exposure to aTr resulted in a decrease in phalloidin labeling in cells to the degree observed in controls, suggesting that aTr may preserve some measures of cell viability (cellular esterase activity (Figure 1), but not maintenance of the actin cytoskeleton. (Figure 3 ). These results also suggest that there are differences in the vitamers tested in their ability to protect RPE from oxidative damage.

To determine if $\alpha \mathrm{T}, \gamma \mathrm{T}, \delta \mathrm{T}$ and $\alpha \mathrm{Tr}$ prevent $\mathrm{tBHP}$-mediated formation of pyknotic nuclei, we measured DAPI-stained nuclei to measure the average nuclear size (Figures 3A,D). 

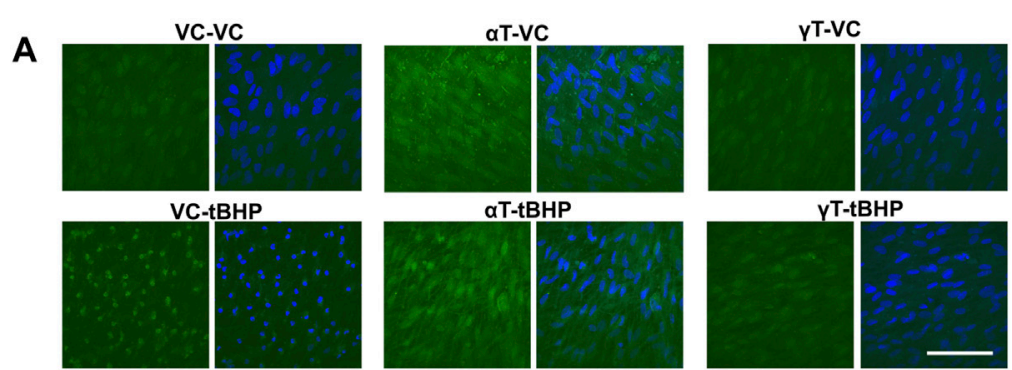

$\alpha \mathrm{T}-\mathrm{tBHP}$

YT-tBHP
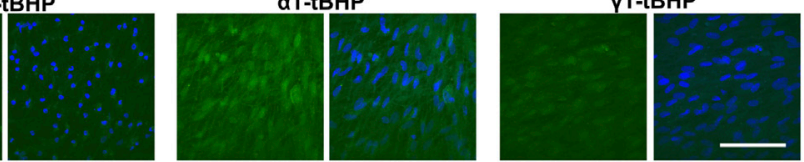

B

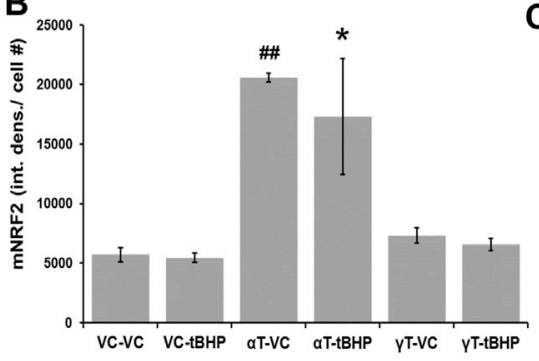

C

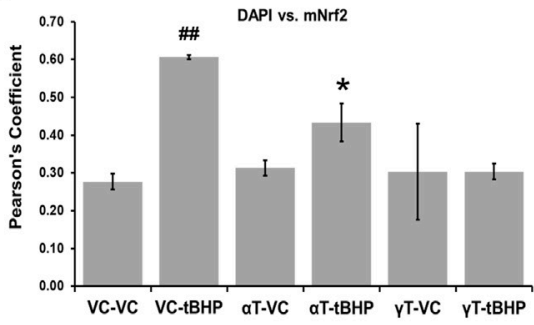

D
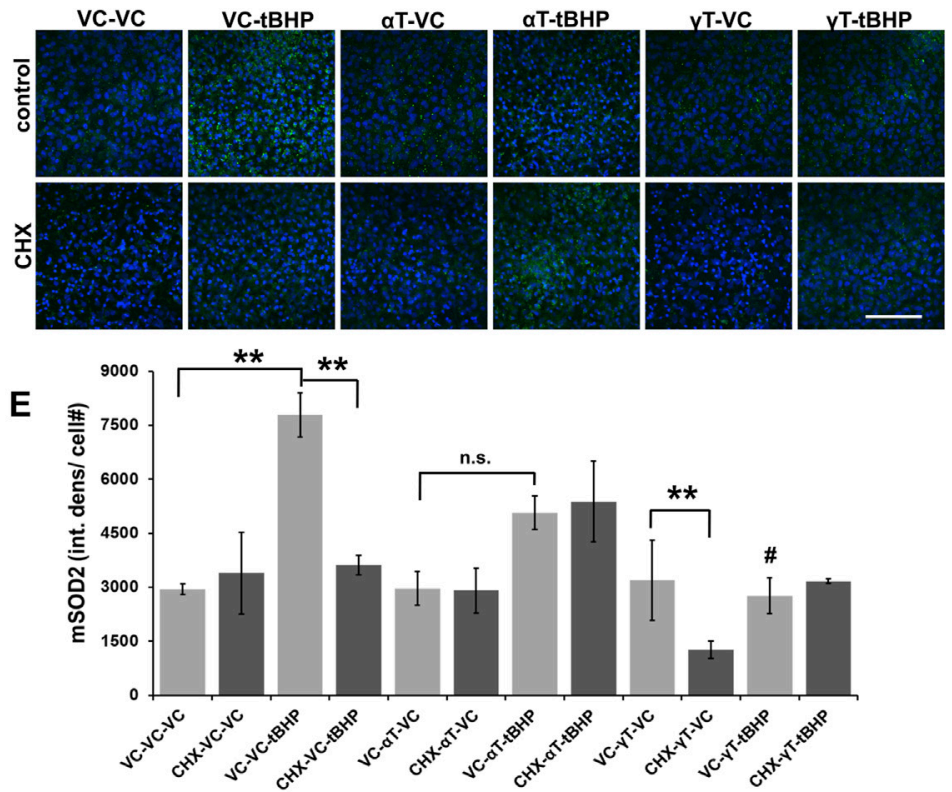

FIGURE 4 | Effect of $\alpha \mathrm{T}, \gamma \mathrm{T}$ and Sublethal Oxidative Stress on Antioxidant Nrf2 and Sod2 Protein Expression. (A) The image panel shows Nrf2 IR (green) and the nucleus (blue) in the presence or absence of a $\mathrm{T}$ or $\gamma \top$ with or without tBHP. Images are 63x magnification and the scale bar is $50 \mu \mathrm{m}$. (B) Quantitative graphical data calculated from images revealed that $\alpha \mathrm{T}$ induced Nrf2 expression (Nrf2 IR) by 3.8-fold. Furthermore, oxidative stress by tBHP had no effect on $\alpha \mathrm{T}$-mediated increase in Nrf2 IR. (C) Colocalization analysis between Nrf2 IR and DAPI fluorescence reveals that tBHP, but not $\alpha \mathrm{T}$ nor $\gamma \mathrm{T}$, leads to Nrf2-DAPI colocalization ( $\left.r^{2}=0.60\right)$. The presence of prevented this tBHP-mediated nuclear translocation of nrf2 and resulting Nrf2-DAPI colocalization. Microfluorimetric analyses are from an average of three images. ${ }^{*} p=\leq 0.05$ versus VC-tBHP, ${ }^{* \# \#} p=\leq 0.01$ versus VC-VC as determined by one-way ANOVA analysis with Bonferroni post hoc test. (D) The image panel shows SOD2 IR (green) and the nucleus (blue) in the presence or absence of $\mathrm{CHX}$ as well as $\alpha \mathrm{T}$ or $\gamma \top$ with or without tBHP. Images are 40x magnification and the scale bar is $100 \mu \mathrm{m}$. (E) Quantitative data calculated from images revealed that exposure of cells to either $\alpha \mathrm{T}$ or $\gamma \mathrm{T}$ had no effect of SOD2 IR, while exposure to sublethal (100 $\mu \mathrm{M}$ ) tBHP led to a 2.6-fold increase in SOD2 IR. Exposure of cells to aT does not significantly reduce tBHP-mediated induction of Sod2. Exposure of cells to $\gamma \top$ led to a $64 \%$ reduction in tBHP-mediated induction of SOD2. Exposure of cells to $\mathrm{CHX}$ had no effect on Sod2 IR, but CHX with $\gamma \mathrm{T}$ led to a $60 \%$ decrease in Sod2 IR. CHX reversed tBHP-mediated induction of Sod2. CHX had no effect on aT's nor $\gamma T^{\prime}$ 's ability to reduce the induction of Sod2 mediated by tBHP. ${ }^{* *} p=\leq 0.01$; n.S. - not significant; ${ }^{*} p=$ $\leq 0.01$ versus VC- $\alpha \mathrm{T}$-tBHP as determined by one-way ANOVA analysis with Bonferroni post hoc test.

None of the vitamin E components alone affected nuclear size or number. Exposure to tBHP led to a $40 \%$ decrease in nuclear size indicative of the nuclear shrinkage (pyknosis) observed in later stages of cell death resembling that of apoptosis (Figures 3A,B). All three tocopherols ( $\alpha \mathrm{T}, \gamma \mathrm{T}$ and $\delta \mathrm{T})$, but not $\alpha \mathrm{Tr}$, prevented tBHP-mediated nuclear shrinkage (pyknosis). 


\section{Effects of $\alpha \mathrm{T}$ and $\gamma \mathrm{T}$ and Sublethal Oxidative Stress on Nrf2 and SOD2 Immunoreactivity}

After establishing sublethal versus lethal concentrations of tBHP for hTERT-RPE cells, we determined what effect $\alpha \mathrm{T}$ and $\gamma \mathrm{T}$ and/ or sublethal tBHP exposures had on the expression of nuclear factor erythroid 2-related factor 2 (Nrf2) and superoxide dismutase 2 (SOD2). We decided to focus on $\alpha \mathrm{T}$ and $\gamma \mathrm{T}$ because 1) much more is known about aT than any other form of tocopherol, and it is generally considered the prototypical tocopherol and 2) $\gamma \mathrm{T}$ is also relatively well studied and it is the most abundant tocopherol from food sources. Furthermore, a few studies have compared the activity of $\alpha \mathrm{T}$ and $\gamma \mathrm{T}$ thereby determining that there are differences in their activity.

$\mathrm{Nrf2}$ is a redox sensitive transcription factor that regulates the expression of genes involved in the cellular antioxidant response while Sod2 is a mitochondrial antioxidant enzyme that is critical for maintaining redox balance in cells (Murakami et al., 1998; Venugopal and Jaiswal, 1998; Itoh et al., 1999; Melov et al., 1999). These proteins were chosen as they should be useful markers for the cellular response against oxidative stress.

Exposure of cells to a $\mathrm{T}$, but not $\gamma \mathrm{T}$, led to a 4 -fold increase in Nrf2 IR while exposure to tBHP had no effect on the amplitude of Nrf2 IR (Figures 4A,B). Exposure of cells to a T followed by tBHP led to a 3.5-fold increase in Nrf2 IR while exposure to $\gamma$ T followed by tBHP had no effect on Nrf2 IR similar to that of tBHP or $\gamma \mathrm{T}$ exposures alone (Figures 4A,B).

To determine what effect $\alpha \mathrm{T}, \gamma \mathrm{T}$ and/or tBHP had on NRf2 nuclear translocation, we measured the colocalization between DAPI DNA stain in the nucleus and Nrf2 IR (Figure 4C). Although exposure to tBHP had no effect on the amplitude of Nrf2 IR, tBHP exposure did increase the amount of Nrf2 IR in the nucleus as determined by an increase in DAPI-Nrf2 colocalization and Pearson's correlation test $\left(\mathrm{r}^{2}=0.61\right.$ (VCtBHP) vs. 0.28 (VC-NT)) (Figure 4C). This suggests that a 24$\mathrm{h}$ period of oxidative stress leads to the nuclear translocation of Nrf2, but not an increase in its expression levels. Alphatocopherol exposure itself for $24 \mathrm{~h}$ led to the upregulation of Nrf2 expression but not Nrf2 nuclear translocation. $\alpha \mathrm{T}$, but not $\gamma \mathrm{T}$, reduced the tBHP-mediated nuclear translocation of Nrf2 by $27 \%$ further highlighting a differential effect between aT and $\gamma \mathrm{T}$ on Nrf2 activity.

Exposure of cells to either a $\mathrm{T}$ or $\gamma \mathrm{T}$ had no effect of SOD2 IR, suggesting that they, themselves, cannot induce SOD2 gene expression (Figures 4D,E). Exposure of cells to sublethal $(100 \mu \mathrm{M}) \mathrm{tBHP}$ for $24 \mathrm{~h}$ led to a 2.6 -fold increase in SOD2 IR, which was expected as others have shown that the Sod2 gene is induced by oxidative stress (Murakami et al., 1998; Melov et al., 1999). Exposure of cells to aT does not significantly reduce tBHP-mediated induction of Sod2, but it shows a trend toward a decrease $(p=0.22)$ (Figure 4E). Exposure of cells to $\gamma \mathrm{T}$ led to a $64 \%$ reduction in $\mathrm{tBHP}-$ mediated induction of SOD2. Together, this suggests that $\gamma \mathrm{T}$ is superior to $\alpha \mathrm{T}$ in reducing the oxidative stress elicited by the level of tBHP needed for Sod2 gene induction.
To determine if synthesis of new proteins is required for tocopherol-mediated cytoprotection, we pre-treated hTERTRPE cells with the protein synthesis inhibitor, cycloheximide, $1 \mathrm{~h}$ prior to tocopherol exposure and $24 \mathrm{~h}$ prior to tBHP exposure.

Exposure of cells to $\mathrm{CHX}$, with or without $\alpha \mathrm{T}$, also had no effect on Sod2 IR, CHX together with $\gamma \mathrm{T}$ led to a $60 \%$ decrease in Sod2 IR (Figure 4E). CHX completely reversed the tBHP-mediated induction of Sod2, suggesting that protein synthesis is required for $\mathrm{tBHP}$ induction of Sod2 (Figure $4 \mathrm{E}$ ). CHX had no effect on aT's nor $\gamma \mathrm{T}$ 's ability to reduce the induction of Sod 2 mediated by $\mathrm{tBHP}$ (Figure 4E), indicating that the mechanism by which these tocopherols reduce tbHP-mediated Sod2 is not dependent upon protein synthesis.

\section{Effects of $\alpha \mathrm{T}$ and $\gamma \mathrm{T}$ on ZO-1 Under Conditions of Oxidative Stress}

RPE barrier function (retinal-blood barrier) is compromised in AMD which prompted us to detect and measure the actin-interacting tight junction protein, ZO-1, as a measure of possible barrier integrity (Penfold et al., 1990). ZO-1 is a protein critical for tight junction formation and reports from others (Pu et al., 2005; Yang et al., 2015), and bioinformatics analysis, suggests that the $\mathrm{ZO}-1$ gene may be regulated by oxidative stress.

We determined whether $\alpha \mathrm{T}$ and $\gamma \mathrm{T}$ and/or sublethal tBHP exposures had on the expression of zona occludens 1 (ZO-1) a critical component of tight junctions in endothelial and epithelial cells, such as RPE (Pu et al., 2005; Yang et al., 2015). ZO-1 directly interacts with multiple proteins in tight junctions and with the actin cytoskeleton (Nybom and Magnusson, 1996; Itoh et al., 1997).

Exposure of cells to either a or $\gamma \mathrm{T}$ had no effect of ZO-1 IR (Figures 5A,B). Exposure of cells to sublethal $(100 \mu \mathrm{M})$ tBHP for $24 \mathrm{~h}$ led to a $63 \%$ increase in $\mathrm{ZO}-1 \mathrm{IR}$, particularly in the nucleus (Figure 5C). Nuclear localization of ZO-1 has been reported elsewhere and has been shown to play a role in multiple cellular functions (Zhong et al., 2012; Guo et al., 2017; Lesage et al., 2017). Similarly, exposure of cells to a $\mathrm{T}$ does not significantly reduce tBHP-mediated induction of $\mathrm{ZO}-1$, but it shows a trend toward a decrease (Figure 5C). Exposure of cells to $\gamma \mathrm{T}$ led to a $50 \%$ reduction in $\mathrm{tBHP}$-mediated induction of $\mathrm{ZO}-1$ (Figure $5 \mathrm{C}$ ). This suggests that, unlike $\alpha \mathrm{T}, \gamma \mathrm{T}$ prevents the effects of $\mathrm{tBHP}$ on $\mathrm{ZO}-1$ expression (Figure 5C), thus is more potent than $\alpha \mathrm{T}$ in maintaining RPE function.

Exposure of cells to CHX, with or without $\alpha \mathrm{T}$ or $\gamma \mathrm{T}$, also had no effect on ZO-1 IR. Addition of the protein synthesis inhibitor, CHX, does not significantly reduce tBHPmediated induction of $\mathrm{ZO}-1$, but it shows a trend toward a decrease (Figure 5C). This suggests that protein synthesis may be a factor in the induction of ZO-1 expression elicited by oxidative stress (tBHP). $\mathrm{CHX}$ and $\alpha \mathrm{T}$ prior to $\mathrm{tBHP}$ exposure, however, had no effect on ZO-1 IR, while CHX completely reversed the ability of $\gamma \mathrm{T}$ to reduce tBHP-mediated increase in ZO-1 IR (Figure 5C). This suggests that, unlike $\alpha \mathrm{T}, \gamma \mathrm{T}$ prevents the effects of $\mathrm{tBHP}$ on ZO-1 expression and these effects require protein synthesis (Figure 5C). 
A

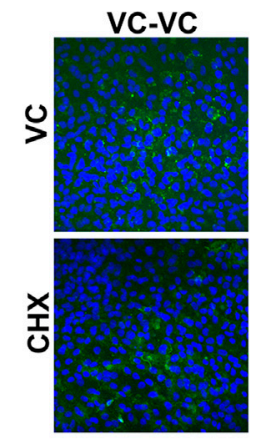

B
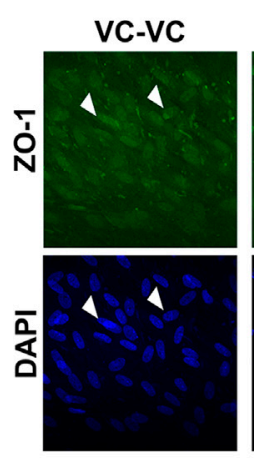
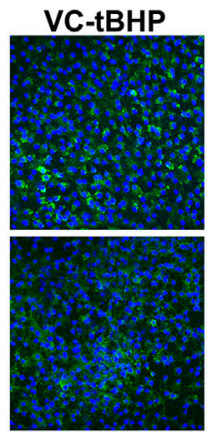

\begin{abstract}
C 12000
\end{abstract}
aT-VC
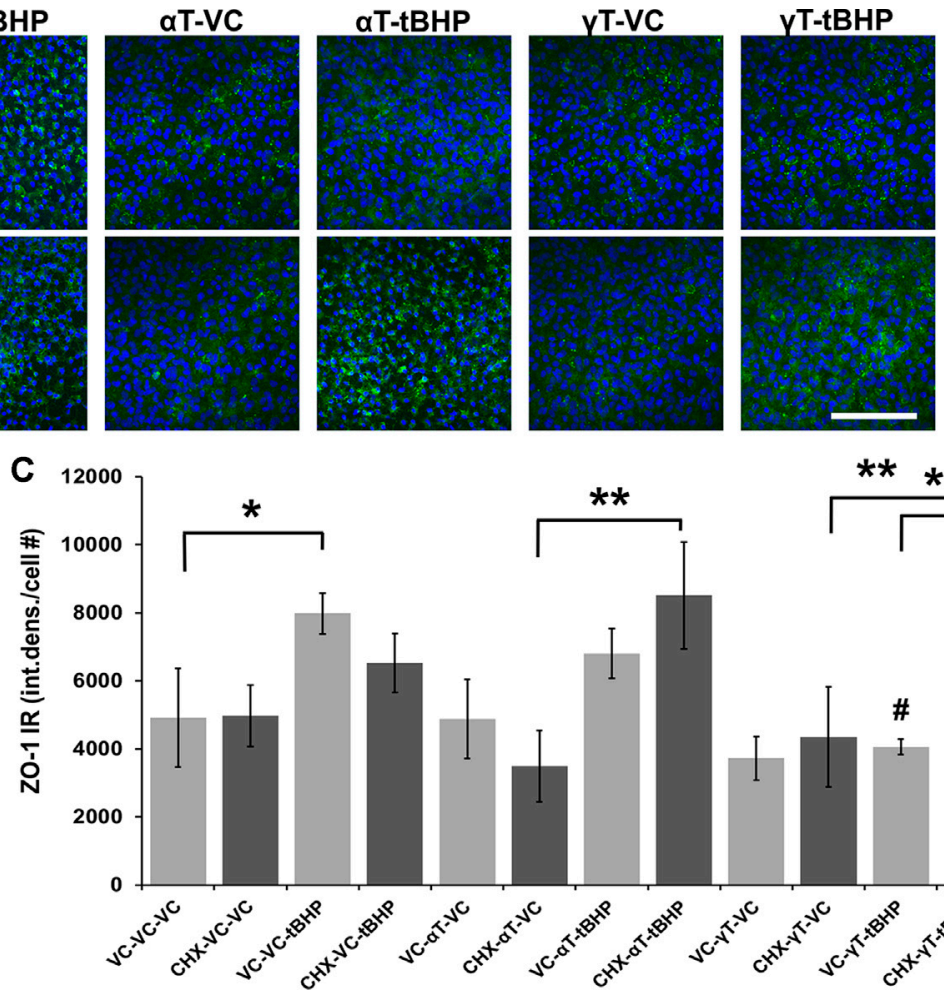

VC-tBHP
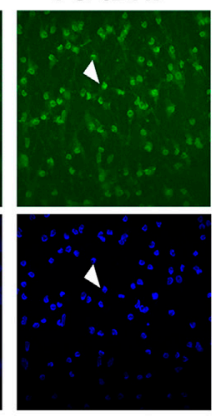

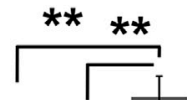

FIGURE 5 | Effect of $\alpha \mathrm{T}, \gamma \mathrm{T}$, Oxidative Stress and Protein Synthesis on ZO-1 Expression. (A) The image panel shows ZO-1 IR (green) and the nucleus (blue) in the presence or absence of $\alpha \mathrm{T}$ or $\gamma \mathrm{T}$, with or without tBHP and with or without CHX. Images are $63 \times$ magnification and the scale bar is $50 \mu \mathrm{m}$. (B) Optically magnified images demonstrating condensed ZO-1 IR (white arrows) and nuclear shrinkage (white arrows) observed under conditions of oxidative stress. (C) Quantitative graphical data calculated from images revealed that tBHP alone, but neither $\alpha \mathrm{T}$ nor $\gamma \top$ alone, induced ZO-1 expression (ZO-1 IR, green) by 2.6-fold. The presence of $\alpha \mathrm{T}$ reduced the effect of tBHP on ZO-1 induction, but it failed to reach statistical significance. The presence of $\gamma \mathrm{T}$, however, completely prevented tBHP's effect on ZO- 1 induction. Furthermore, inhibition of protein synthesis with $\mathrm{CHX}$ did not significantly affect tBHP-mediated ZO-1 induction nor aT-tBHP's effect on ZO-1 IR. CHX, however, completely prevented $\gamma$ T's reversal of tBHP-mediated ZO- 1 induction. Microfluorimetric analyses are from an average of three images. ${ }^{*} p=\leq 0.05,{ }^{* *} p=\leq 0.01$ with $t B H P$ versus the same condition without tBHP as determined by one-way ANOVA analysis with Bonferroni post hoc test.

\section{Effects of $\alpha \mathrm{T}$ and $\gamma \mathrm{T}$ on Nuclear Shrinkage Under Conditions of Severe Oxidative Stress}

Quantitation of pyknotic nuclei, nuclei that appear to be half or less the size of normal nuclei, were counted and expressed as a percentage of the total (Figures 6A,B). Exposure of cells to tBHP led to a $37 \%$ increase in nuclear pyknosis compared to controls (Figure 6B). Exposure of cells to a $\mathrm{T}$ or $\gamma \mathrm{T}$ had no effect on baseline nuclear pyknosis. Exposure of cells to a $\mathrm{T}$ or $\gamma \mathrm{T}$ decrease tBHP-mediated nuclear pyknosis by 55 and $89 \%$, respectively (Figure 6B).

Pretreatment of cells with CHX, itself, lead to a 4.3-fold increase in nuclear pyknosis compared to control not treated with CHX (13\% overall increase) (Figure 6B). CHX treatment prior to $\mathrm{tBHP}$, led to a $10 \%$ decrease in nuclear pyknosis compared to tBHP alone (5\% decrease overall), suggesting that protein synthesis is required, in part, for nuclear pyknosis. Pretreatment of cells with $\mathrm{CHX}$ prior to aT led to an 18 -fold increase the nuclear pyknosis compared to cells exposed to aT alone (19\% overall increase in nuclear pyknosis (Figure 6B). Exposure of cells to CHX prior to a $\mathrm{T}$ and $\mathrm{tBHP}$ led to a 1.7-fold increase in nuclear pyknosis (13\% overall increase) compared to $\alpha \mathrm{T}$ and $\mathrm{tBHP}$ without $\mathrm{CHX}$ pre-exposure, suggesting that some protein synthesis is required for a $\mathrm{T}$ to reduce $\mathrm{tBHP}$-mediated nuclear shrinkage.

Pretreatment of cells with CHX prior to $\gamma \mathrm{T}$ led to an 11-fold increase the nuclear pyknosis compared to cells exposed to $\gamma \mathrm{T}$ alone (31\% overall increase in nuclear pyknosis) (Figures 6A,B). Exposure of cells to CHX prior to $\gamma \mathrm{T}$ and tBHP led to a 2-fold increase in nuclear pyknosis (5\% overall increase) compared to $\gamma \mathrm{T}$ and $\mathrm{tBHP}$ without $\mathrm{CHX}$ pre-exposure, suggesting that some protein synthesis is required for $\gamma \mathrm{T}$ to reduce $\mathrm{tBHP}$-mediated cell death (Figure 6).

\section{DISCUSSION}

Here, we determined that specific vitamin E components exhibit unique cytoprotective properties in immortalized human RPE cells. We used supraphysiological concentrations of $\gamma \mathrm{T}, \delta \mathrm{T}$ and $\alpha \operatorname{Tr}$ to ascertain whether they exhibit similar cytoprotective activity as aT. In addition, we determined whether short-term versus longer-term exposure to tocopherols leads to similar 

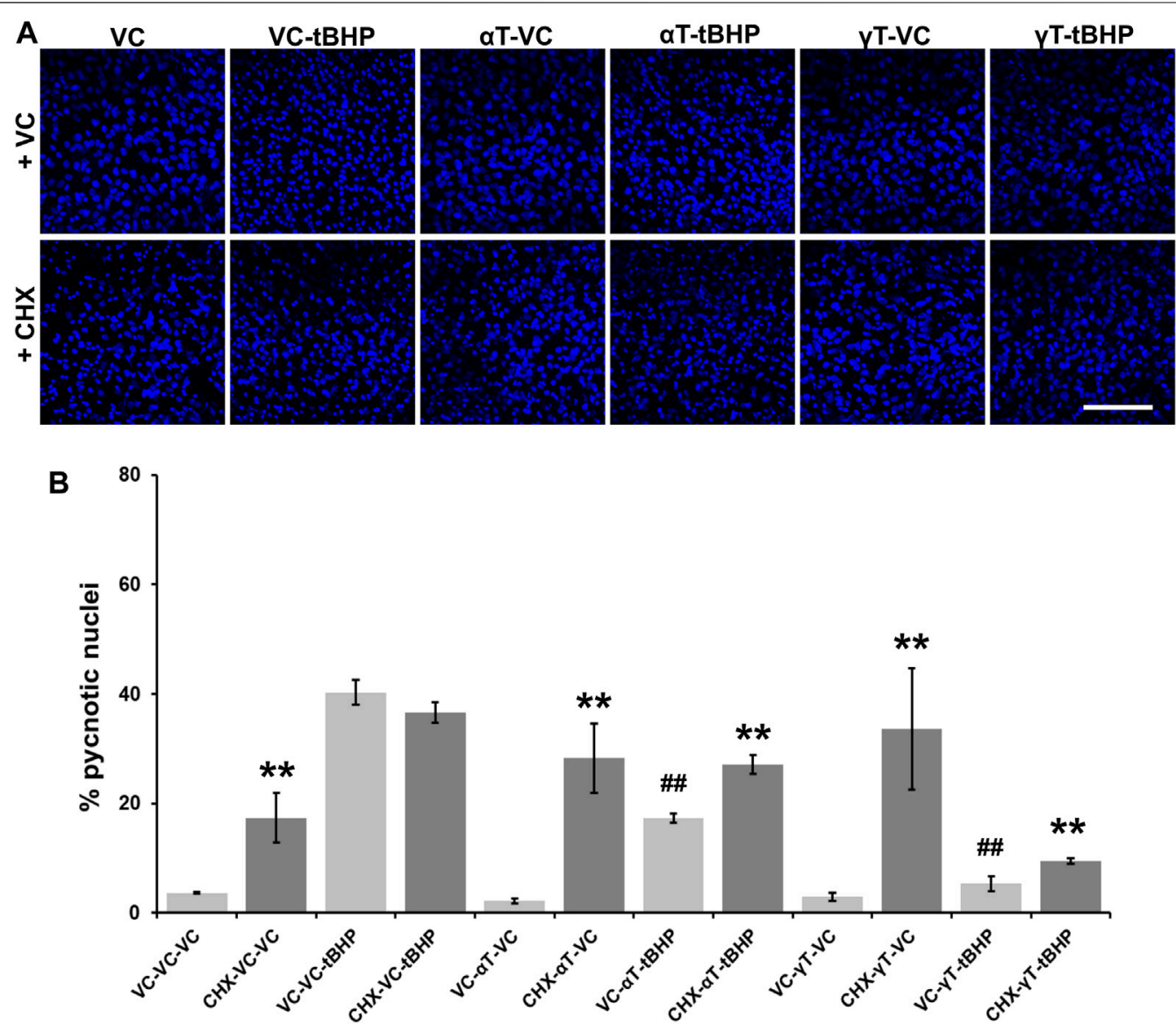

FIGURE 6 | Effect of $\mathrm{CHX}$ and long-term (24-h) tocopherol exposure of hTERT-RPE cells on tBHP-mediated cytotoxicity. hTERT-RPE cells were exposed to CHX for $1 \mathrm{~h}$ followed by $\alpha \mathrm{T}$ or $\gamma \top$ for $24 \mathrm{~h}$ prior to tBHP. (A) Image panels showing DAPI labeling of nuclei (blue) in cells exposed to $\mathrm{CHX}$, aT or $\gamma \top$ and tBHP. Top row represents conditions without $\mathrm{CHX}$ while the bottom row represents conditions with $\mathrm{CHX}$. Nucleus area (blue fluorescence) is reduced during cell death by a process resembling apoptosis. Images acquired at 40x magnification; scale bar is $100 \mu \mathrm{m}$. (B) Measurement of pyknotic nuclei, nuclei that are half the size of average normal nuclei and not merely reduced in size, was carried out on $\mathrm{CHX}$-, tocopherol- and tBHP-exposed cells. Exposure of cells to $\mathrm{CHX}$ (dark bars) alone increases the percentage of pyknotic nuclei in the cell population from 4\% in control cells (light bars) to 17\%. Exposure of cells to tBHP led to an increase in the percentage of pyknotic nuclei from 4 to $40 \%$. Exposure of cells to either tocopherol alone had no effect on the percentage of pyknotic nuclei, but exposure to $\mathrm{CHX}$ and tocopherols led to an increase in the percentage of pyknotic nuclei from 2 to $28 \%$ for $\alpha \mathrm{T}$ and $3-34 \%$ for $\gamma \top$. The presence of $\alpha \mathrm{T}$ prior to tBHP insult reduced the percentage of pyknotic nuclei by $57 \%$ compared to cells treated with tBHP alone. Inhibition of protein synthesis by $\mathrm{CHX}$ partially reversed this aT protection by $47 \%$. The presence of $\gamma \mathrm{T}$ prior to tBHP insult reduced the percentage of pyknotic nuclei by $87 \%$ compared to cells treated with tBHP alone. Inhibition of protein synthesis by $\mathrm{CHX}$ partially reversed this $\gamma \top$ protection by $44 \%$. Microfluorimetric analyses are from an average of three images. ${ }^{\star \star} p \leq 0.01$ with $\mathrm{CHX}$ versus the same condition without $\mathrm{CHX}$, ${ }^{\# \#} p \leq 0.01$ with $\mathrm{tBHP}$ versus the same condition without tBHP as determined by one-way ANOVA analysis with Bonferroni post hoc test.

degree of cytoprotection against oxidative stress and cell death. Both $\gamma \mathrm{T}, \delta \mathrm{T}$ and $\alpha \mathrm{Tr}$ require less time than aT to protect cells against $\mathrm{tBHP}$, suggesting that $\alpha \mathrm{T}$ acts through a different mechanism of action than direct antioxidant activity to exert its full protective effects. We focused primarily on $\alpha \mathrm{T}$ and $\gamma \mathrm{T}$ because there are more published studies on these two tocopherols than other vitamin E components and they are metabolized differently (Azzi, 2018; Uchida et al., 2018). Our results suggest that $\alpha \mathrm{T}$ and $\gamma \mathrm{T}$ exhibit different kinetics and/or potencies for antioxidant activity, different effects on Nrf2 expression and different effects on actin stability, Sod2 and ZO-1 expression meditated by oxidative stress. As a result of our data, the selection of specific tocopherol vitamers as therapeutic antioxidants may need to be considered, particularly $\gamma \mathrm{T}$, due to its different pharmacokinetic and pharmacodynamic properties than $a \mathrm{~T}$.

To our knowledge, this study is the first measuring the comparative kinetics and cytoprotective efficacy between aT and $\gamma \mathrm{T}$ against oxidative damage, the expression and subcellular localization of antioxidant and structural proteins, and the requirement for protein synthesis for these effects in RPE cells.

Many plant-based vitamin E sources contain predominantly $\gamma \mathrm{T}$ and lesser concentrations of other tocopherols (Jiang et al., 2001; Szewczyk et al., 2021). Since North American diets contain more $\gamma \mathrm{T}$ than other tocopherols, higher levels of $\gamma \mathrm{T}$ tocopherol are ingested, but it is more rapidly eliminated from the body (in bile). $a \mathrm{~T}$, on the other 
hand, persists at higher plasma concentrations due to much greater retention in the body. There are conflicting reports about which tocopherol form exhibits the most potent antioxidant activity (Kamal-Eldin and Appelqvist, 1996). Based on literature, the upper physiologic concentration of vitamin $\mathrm{E}$ in mammals is in the low micromolar range $(<25 \mu \mathrm{M})$ (Arigony et al., 2013; Jamro et al., 2019). Based on this we chose to use $100 \mathrm{uM}$ tocopherols and tocotrienols, as this concentration is up to 10 times higher than concentrations achieved through a normal diet but could still be achieved using dietary supplementation.

We selected a short (4-h) tocopherol exposure time based on the assumption that it would not allow for as much cellular uptake through tocopherol transport proteins as the 24-h exposure period. Therefore, the shorter 4-h tocopherol exposure period was a better approach for determining the direct antioxidant effect while the 24-h period was a better approach for looking at cellular uptake and subsequent cell signaling, in addition to direct antioxidant properties.

Our rationale for selecting the measurement of actin, nuclei, $\mathrm{Nrf}$, Sod2 and ZO-1 is based on numerous studies where the detection and measurement of these proteins serve to assess the functional integrity (actin and $\mathrm{ZO}-1$ ) and cellular response to oxidative stress (Nrf2 and Sod2) and viability (actin and nuclear staining) of epithelial cells (Penfold et al., 1990; Murakami et al., 1998; Venugopal and Jaiswal, 1998; Itoh et al., 1999; Melov et al., 1999; Pu et al., 2005; Yang et al., 2015).

To assess cell death in RPE in response to tBHP, we labeled actin filaments with fluorescently tagged phalloidin. Phalloidin is a cell permeable phallotoxin from the death cap mushroom that binds with high affinity to filamentous actin, but not depolymerized or monomeric actin (Cooper, 1987). During apoptotic cell death, some components of the cytoskeleton, including actin, have been shown to become destabilized or relocate to the periphery of the cell (Reed, 1995). As a result, hTERT-RPE cells exposed to tBHP exhibit reduced filamentous actin and phalloidin labeling. DAPI labels DNA in cells and during apoptotic cell death, nuclear condensation occurs. During this process, DNA migrates to the periphery of the nucleus near the nuclear envelope as part of a process called pyknosis (Reed, 1995). hTERT-RPE cells exposed to tBHP resulted in pyknotic nuclei. Since we did not measure caspase activation or other direct apoptotic markers, we could not prove that cell death was carried out by an apoptotic process. In this study, however, we were more interested in observing and measuring cellular morphology than a specific apoptotic process.

Since Nrf2 is a major regulator of the cellular antioxidant response, we decided to measure the effect of tBHP and tocopherols on its expression. We predicted that tBHP, and not tocopherols themselves, would increase Nrf2 expression. Much to our surprise, however, tBHP had no effect on Nrf2 expression but $\alpha \mathrm{T}$, not $\gamma \mathrm{T}$, did. The only effect of tBHP we were able to observe was the relative increase in nuclear Nrf2 IR compared to other treatments. Our results indicate that $\alpha \mathrm{T}$ itself can upregulate Nrf2 expression, thereby potentially priming the RPE cells for a more effective antioxidant response. Interestingly, $\alpha \mathrm{T}$, but not $\gamma \mathrm{T}$, was able to reduce
tBHP-mediated Nrf2 nuclear translocation suggesting that $\alpha \mathrm{T}$ ang $\gamma \mathrm{T}$ exhibit differential effects on Nrf2 activity.

Sod2 is an important antioxidant enzyme located in mitochondria, a common source of free radical formation (Murakami et al., 1998; Melov et al., 1999). We determine whether tBHP induces Sod2 expression because it has been shown in multiple studies to become induced in response to oxidative stress (Murakami et al., 1998; Melov et al., 1999). We also determined whether tocopherols could affect Sod 2 expression. As expected, tBHP increased Sod2 IR, but neither $\alpha$ T nor $\gamma$ T had an effect on Sod2 IR. In fact, $\gamma \mathrm{T}$, and to a lesser extent, $\alpha \mathrm{T}$, decreased Sod2 IR elicited by tBHP. Since inhibiting protein synthesis with $\mathrm{CHX}$ didn't change the inhibitory effect of $\alpha \mathrm{T}$ or $\gamma \mathrm{T}$ on $\mathrm{tBHP}$-mediate-Sod 2 expression, we conclude that these effects of $\alpha \mathrm{T}$ and $\gamma \mathrm{T}$ may not require the synthesis of new protein.

We determined whether $\mathrm{tBHP}$, $\alpha \mathrm{T}$ or $\gamma \mathrm{T}$ or a combination of tocopherols and tBHP had an effect on the expression of the tight junction and actin-binding protein, $\mathrm{ZO}-1$. We reasoned that a reduction or redistribution of $\mathrm{ZO}-1$ may have significant negative ramifications for RPE tissue integrity and barrier function while an increase in ZO-1 IR would represent improvement in RPE function. Both tBHP and $\alpha \mathrm{T}$, alone, led to an increase in ZO-1 IR and the combination of both led to an additive increase in ZO-1. ZO-1 IR in these cells was predominantly nuclear and not located at the plasma membrane where one would expect to see it. Several reports have identified nuclear localization of ZO-1 which corroborate our findings. For example, in lung and breast tumor cells, ZO-1 has been observed in cytonuclear compartments and is involved in NFkB signaling (Lesage et al., 2017). The HIV Tat proteins has been shown to alter the expression pattern of ZO-1 in murine brain endothelial cells (Pu et al., 2005) and to cause nuclear localization of ZO-1 in human brain vascular endothelial cells (Zhong et al., 2012). The observation that ZO-1 is expressed on the cell surface and in the cytoplasmic and nuclear regions is interesting, but the ramifications for these different expression patterns are not clear.

The upregulation of ZO- 1 by $\alpha \mathrm{T}, \mathrm{tBHP}$ and both $\alpha \mathrm{T}$ and $\mathrm{tBHP}$ suggest that, 1) a T may help protect barrier function by creating more cellular ZO-1 protein, 2) cells may respond to oxidative stress by upregulating ZO-1 to help maintain proper barrier and, 3 ) the presence of both produce an additive effect. The fact that $\gamma \mathrm{T}$ does not have the same effect on ZO-1 expression indicates that the two tocopherols exhibit different activities or interact with different cellular processes.

Cycloheximide inhibits protein synthesis by preventing the translocation of transfer RNA in the ribosomal active site. To determine if protein synthesis is required for tocopherol's protective effects, we exposed cells to CHX $1 \mathrm{~h}$ before the addition of tocopherols so that the inhibition of protein synthesis would occur before, or in the early stages of, tocopherol-mediated signal transduction. The presence of CHX should not have any effect on tocopherols direct antioxidant activities. $\mathrm{CHX}$ can be toxic to some cells at concentrations needed to block protein synthesis, so we removed the CHX within $1 \mathrm{~h}$, when the tocopherols were added, to allow cells to recover from its toxic effects prior to exposing cells to tBHP. CHX and tBHP toxicity are not additive; this suggests that, as expected, the mechanism of action of $\mathrm{CHX}$ and $\mathrm{tBHP}$ are mutually exclusive. 
Future studies need to be carried out to determine whether $\alpha \mathrm{T}, \gamma \mathrm{T}$ and $\delta \mathrm{T}$ can affect RPE function, particularly the secretion of neurotrophic and protective factors, uptake of shed photoreceptor outer segments and barrier function as determined by transepithelial resistance. In addition, several questions regarding the in vitro and in vivo kinetics and potency of different tocopherol and tocotrienols must be answered. It is also reasonable to assume that specific tocopherol-tocotrienol combination formulations, together with localized delivery methods, in lieu of systemic administration, may provide great therapeutic potential in diseases where oxidative stress is a major contributor.

\section{DATA AVAILABILITY STATEMENT}

The original contributions presented in the study are included in the article/Supplementary Material, further inquiries can be directed to the corresponding author.

\section{AUTHOR CONTRIBUTIONS}

PK conceived and designed the experiments. RSD, DTH, and $\mathrm{CWH}$ performed the experiments. All authors analyzed the data.

\section{REFERENCES}

Age-Related Eye Disease Study 2 Research Group (2013). Lutein + Zeaxanthin and omega-3 Fatty Acids for Age-Related Macular Degeneration: The Age-Related Eye Disease Study 2 (AREDS2) Randomized Clinical Trial. JAMA 309 (19), 2005-2015. doi:10.1001/jama.2013.4997

Age-Related Eye Disease Study Research Group (2001). A Randomized, PlaceboControlled, Clinical Trial of High-Dose Supplementation with Vitamins C and E, Beta Carotene, and Zinc for Age-Related Macular Degeneration and Vision Loss: AREDS Report No. 8. Arch. Ophthalmol. 119 (10), 1417-1436. doi:10.1001/archopht.119.10.1417

Agrón, E., Mares, J., Clemons, T. E., Swaroop, A., Chew, E. Y., Keenan, T. D. L., et al. (2021). Dietary Nutrient Intake and Progression to Late Age-Related Macular Degeneration in the Age-Related Eye Disease Studies 1 and 2. Ophthalmology 128 (3), 425-442. doi:10.1016/j.ophtha.2020.08.018

Arigony, A. L., de Oliveira, I. M., Machado, M., Bordin, D. L., Bergter, L., Prá, D., et al. (2013). The Influence of Micronutrients in Cell Culture: A Reflection on Viability and Genomic Stability. Biomed. Res. Int. 2013, 597282. doi:10.1155/ 2013/597282

Azzi, A. (2018). Many Tocopherols, One Vitamin E. Mol. Aspects Med. 61, 92-103. doi:10.1016/j.mam.2017.06.004

Borras, C., Canonica, J., Jorieux, S., Abache, T., El Sanharawi, M., Klein, C., et al. (2019). CFH Exerts Anti-Oxidant Effects on Retinal Pigment Epithelial Cells Independently from Protecting Against Membrane Attack Complex. Sci. Rep. 9 (1), 13873. doi:10.1038/s41598-019-50420-9

Cabral de Guimaraes, T. A., Daich Varela, M., Georgiou, M., and Michaelides, M. (2021). Treatments for Dry Age-Related Macular Degeneration: Therapeutic Avenues, Clinical Trials and Future Directions. Br. J. Ophthalmol. bjophthalmol-2020-318452. Online ahead of print. doi:10.1136/ bjophthalmol-2020-318452

Chakravarthy, U., Augood, C., Bentham, G. C., de Jong, P. T., Rahu, M., Seland, J., et al. (2007). Cigarette Smoking and Age-Related Macular Degeneration in the EUREYE Study. Ophthalmology 114 (6), 1157-1163. doi:10.1016/ j.ophtha.2006.09.022

Chew, E. Y., Clemons, T. E., Agrón, E., Sperduto, R. D., Sangiovanni, J. P., Kurinij, N., et al. (2013). Long-Term Effects of Vitamins $C$ and E, $\beta$-Carotene, and Zinc
RSD and PK wrote the paper. All authors edited and reviewed the paper.

\section{FUNDING}

Research reported in this publication was supported in part by grants from the National Eye Institute (EY030747), the National Center for Research Resources and National Institute of General Medical Sciences (RR027093) of the National Institutes of Health (PK). The content is solely the responsibility of the authors and does not necessarily represent the official views of the National Institutes of Health. Additional support by the Felix and Carmen Sabates Missouri Endowed Chair in Vision Research, a Challenge Grant from Research to Prevent Blindness and the Vision Research Foundation of Kansas City is gratefully acknowledged.

\section{ACKNOWLEDGMENTS}

Support by Sean Riordan, Genea Edwards, Andrew Keightley and Megan Florance is gratefully acknowledged. The authors thank Margaret, Richard and Sara Koulen for generous support and encouragement.

on Age-Related Macular DegenerationLong-Term Effects of Vitamins C and E, Beta-Carotene, and Zinc on Age-Related Macular Degeneration: AREDS Report No. 35. Ophthalmology 120 (8), 1604-1611. doi:10.1016/ j.ophtha.2013.01.021

Chiricosta, L., Gugliandolo, A., Tardiolo, G., Bramanti, P., and Mazzon, E. (2019). Transcriptomic Analysis of MAPK Signaling in NSC-34 Motor Neurons Treated with Vitamin E. Nutrients 11 (5), 1081. doi:10.3390/nu11051081

Cooper, J. A. (1987). Effects of Cytochalasin and Phalloidin on Actin. J. Cel Biol 105 (4), 1473-1478. doi:10.1083/jcb.105.4.1473

Dalvi, S., Galloway, C. A., Winschel, L., Hashim, A., Soto, C., Tang, C., et al. (2019). Environmental Stress Impairs Photoreceptor Outer Segment (POS) Phagocytosis and Degradation and Induces Autofluorescent Material Accumulation in hiPSC-RPE Cells. Cell Death Discov 5, 96-16. doi:10.1038/ s41420-019-0171-9

Ding, Y., Fan, J., Fan, Z., and Zhang, K. (2021). $\gamma$-Tocotrienol Reverses Multidrug Resistance of Breast Cancer Cells through the Regulation of the $\gamma$-TocotrienolNF-кB-P-gp axis. J. Steroid Biochem. Mol. Biol. 209, 105835. doi:10.1016/ j.jsbmb.2021.105835

Duncan, R. S., Hwang, S. Y., and Koulen, P. (2007). Differential Inositol 1,4,5Trisphosphate Receptor Signaling in a Neuronal Cell Line. Int. J. Biochem. Cel Biol 39 (10), 1852-1862. doi:10.1016/j.biocel.2007.05.003

Edwards, A. O., Ritter, R., 3rd, Abel, K. J., Manning, A., Panhuysen, C., and Farrer, L. A. (2005). Complement Factor H Polymorphism and Age-Related Macular Degeneration. Science 308 (5720), 421-424. doi:10.1126/ science. 1110189

Fleckenstein, M., Keenan, T. D. L., Guymer, R. H., Chakravarthy, U., SchmitzValckenberg, S., Klaver, C. C., et al. (2021). Age-Related Macular Degeneration. Nat. Rev. Dis. Primers 7 (1), 31. doi:10.1038/s41572-021-00265-2

Fletcher, A. E., Bentham, G. C., Agnew, M., Young, I. S., Augood, C., Chakravarthy, U., et al. (2008). Sunlight Exposure, Antioxidants, and Age-Related Macular Degeneration. Arch. Ophthalmol. 126 (10), 1396-1403. doi:10.1001/ archopht.126.10.1396

Ghani, S. M. A., Goon, J. A., Azman, N. H. E. N., Zakaria, S. N. A., Hamid, Z., and Ngah, W. Z. W. (2019). Comparing the Effects of Vitamin E Tocotrienol-Rich Fraction Supplementation and $\alpha$-Tocopherol Supplementation on Gene Expression in Healthy Older Adults. Clinics (Sao Paulo) 74, e688. doi:10.6061/clinics/2019/e688 
Gugliandolo, A., Chiricosta, L., Silvestro, S., Bramanti, P., and Mazzon, E. (2019). a-Tocopherol Modulates Non-Amyloidogenic Pathway and Autophagy in an In Vitro Model of Alzheimer's Disease: A Transcriptional Study. Brain Sci. 9 (8), 196. doi:10.3390/brainsci9080196

Guo, J., Cai, H., Zheng, J., Liu, X., Liu, Y., Ma, J., et al. (2017). Long Non-Coding RNA NEAT1 Regulates Permeability of the Blood-Tumor Barrier via miR181d-5p-Mediated Expression Changes in ZO-1, Occludin, and Claudin-5. Biochim. Biophys. Acta Mol. Basis Dis. 1863 (9), 2240-2254. doi:10.1016/ j.bbadis.2017.02.005

Hageman, G. S., Anderson, D. H., Johnson, L. V., Hancox, L. S., Taiber, A. J., Hardisty, L. I., et al. (2005). A Common Haplotype in the Complement Regulatory Gene Factor $\mathrm{H}(\mathrm{HF} 1 / \mathrm{CFH})$ Predisposes Individuals to AgeRelated Macular Degeneration. Proc. Natl. Acad. Sci. U S A. 102 (20), 7227-7232. doi:10.1073/pnas.0501536102

Hageman, G. S., Luthert, P. J., Victor Chong, N. H., Johnson, L. V., Anderson, D. H., and Mullins, R. F. (2001). An Integrated Hypothesis that Considers Drusen as Biomarkers of Immune-Mediated Processes at the RPE-Bruch's Membrane Interface in Aging and Age-Related Macular Degeneration. Prog. Retin. Eye Res. 20 (6), 705-732. doi:10.1016/s1350-9462(01)00010-6

He, Y., and Tombran-Tink, J. (2010). Mitochondrial Decay and Impairment of Antioxidant Defenses in Aging RPE Cells. Adv. Exp. Med. Biol. 664, 165-183. doi:10.1007/978-1-4419-1399-9_20

Hensley, K., Benaksas, E. J., Bolli, R., Comp, P., Grammas, P., Hamdheydari, L., et al. (2004). New Perspectives on Vitamin E: Gamma-Tocopherol and Carboxyelthylhydroxychroman Metabolites in Biology and Medicine. Free Radic. Biol. Med. 36 (1), 1-15. doi:10.1016/j.freeradbiomed.2003.10.009

Hidalgo, M., Rodríguez, V., Kreindl, C., and Porras, O. (2020). Biological Redox Impact of Tocopherol Isomers Is Mediated by Fast Cytosolic Calcium Increases in Living Caco-2 Cells. Antioxidants (Basel) 9 (2), 155. doi:10.3390/ antiox9020155

Hosomi, A., Arita, M., Sato, Y., Kiyose, C., Ueda, T., Igarashi, O., et al. (2019). Affinity for Alpha-Tocopherol Transfer Protein as a Determinant of the Biological Activities of Vitamin E Analogs. FEBS Lett. 409, 105-108. doi:10.1016/s0014-5793(97)00499-7

Itoh, K., Ishii, T., Wakabayashi, N., and Yamamoto, M. (1999). Regulatory Mechanisms of Cellular Response to Oxidative Stress. Free Radic. Res. 31 (4), 319-324. doi:10.1080/10715769900300881

Itoh, M., Nagafuchi, A., Moroi, S., and Tsukita, S. (1997). Involvement of ZO-1 in Cadherin-Based Cell Adhesion through its Direct Binding to Alpha Catenin and Actin Filaments. J. Cel Biol 138 (1), 181-192. doi:10.1083/ jcb.138.1.181

Jamro, E. L., Bloom, M. S., Browne, R. W., Kim, K., Greenwood, E. A., and Fujimoto, V. Y. (2019). Preconception Serum Lipids and Lipophilic Micronutrient Levels Are Associated with Live Birth Rates after IVF. Reprod. Biomed. Online 39 (4), 665-673. doi:10.1016/j.rbmo.2019.06.004

Jiang, Q., Christen, S., Shigenaga, M. K., and Ames, B. N. (2001). GammaTocopherol, the Major Form of Vitamin E in the US Diet, Deserves More Attention. Am. J. Clin. Nutr. 74 (6), 714-722. doi:10.1093/ajcn/74.6.714

Kamal-Eldin, A., and Appelquist, L. A. (1996). The Chemistry and Antioxidant Properties of Tocopherols and Tocotrienols. Lipids 31 (7), 671-701. doi:10.1007/BF02522884

Khan, J. C., Thurlby, D. A., Shahid, H., Clayton, D. G., Yates, J. R., Bradley, M., et al. (2006). Smoking and Age Related Macular Degeneration: The Number of Pack Years of Cigarette Smoking Is a Major Determinant of Risk for Both Geographic Atrophy and Choroidal Neovascularisation. Br. J. Ophthalmol. 90 (1), 75-80. doi:10.1136/bjo.2005.073643

Kunchithapautham, K., Atkinson, C., and Rohrer, B. (2014). Smoke Exposure Causes Endoplasmic Reticulum Stress and Lipid Accumulation in Retinal Pigment Epithelium through Oxidative Stress and Complement Activation. J. Biol. Chem. 289 (21), 14534-14546. doi:10.1074/jbc.M114.564674

Laster, S. M., and Mackenzie, J. M., Jr (1996). Bleb Formation and F-Actin Distribution during Mitosis and Tumor Necrosis Factor-Induced Apoptosis. Microsc. Res. Tech. 34 (3), 272-280. doi:10.1002/(SICI)1097-0029(19960615) 34::3<272:AID-JEMT10>3.0.CO;2-J

Lesage, J., Suarez-Carmona, M., Neyrinck-Leglantier, D., Grelet, S., Blacher, S., Hunziker, W., et al. (2017). Zonula Occludens-1/nf-Kb/cxcl8: A New Regulatory axis for Tumor Angiogenesis. FASEB J. 31 (4), 1678-1688. doi:10.1096/fj.201600890R
Levee, M. G., Dabrowska, M. I., Lelli, J. L., Jr, and Hinshaw, D. B. (1996). Actin Polymerization and Depolymerization during Apoptosis in HL-60 Cells. Am. J. Physiol. 271 (6 Pt 1), C1981-C1992. doi:10.1152/ajpcell.1996.271.6.C1981

Liu, D., Chan, S. L., de Souza-Pinto, N. C., Slevin, J. R., Wersto, R. P., Zhan, M., et al. (2006). Mitochondrial UCP4 Mediates an Adaptive Shift in Energy Metabolism and Increases the Resistance of Neurons to Metabolic and Oxidative Stress. Neuromolecular Med. 8 (3), 389-414. doi:10.1385/NMM:8:3:389

Marazita, M. C., Dugour, A., Marquioni-Ramella, M. D., Figueroa, J. M., and Suburo, A. M. (2016). Oxidative Stress-Induced Premature Senescence Dysregulates VEGF and CFH Expression in Retinal Pigment Epithelial Cells: Implications for Age-Related Macular Degeneration. Redox Biol. 7, 78-87. doi:10.1016/j.redox.2015.11.011

Matsura, T. (2019). Protective Effect of Tocotrienol on In Vitro and In Vivo Models of Parkinson's Disease. J. Nutr. Sci. Vitaminol (Tokyo) 65 (Supplment), S51-S53. doi:10.3177/jnsv.65.S51

Mehrabi, S., Nasirinezhad, F., Barati, M., Abutaleb, N., Barati, S., Dereshky, B. T., et al. (2019). The Effect of Alpha-Tocopherol on Morphine Tolerance-Induced Expression of C-Fos Proto-Oncogene from a Biotechnological Perspective. Recent Pat Biotechnol. 13 (2), 137-148. doi:10.2174/ 1872208312666181120105333

Melov, S., Coskun, P., Patel, M., Tuinstra, R., Cottrell, B., Jun, A. S., et al. (1999). Mitochondrial Disease in Superoxide Dismutase 2 Mutant Mice. Proc. Natl. Acad. Sci. U S A. 96 (3), 846-851. doi:10.1073/pnas.96.3.846

Moore, C., Palau, V. E., Mahboob, R., Lightner, J., Stone, W., and Krishnan, K. (2020). Upregulation of pERK and C-JUN by $\gamma$-Tocotrienol and Not a-tocopherol Are Essential to the Differential Effect on Apoptosis in Prostate Cancer Cells. BMC Cancer 20 (1), 428. doi:10.1186/s12885-02006947-6

Müller, A. S., and Pallauf, J. (2003). Effect of Increasing Selenite Concentrations, Vitamin E Supplementation and Different Fetal Calf Serum Content on GPx1 Activity in Primary Cultured Rabbit Hepatocytes. J. Trace Elem. Med. Biol. 17 (3), 183-192. doi:10.1016/S0946-672X(03)80024-X

Murakami, K., Kondo, T., Kawase, M., Li, Y., Sato, S., Chen, S. F., et al. (1998). Mitochondrial Susceptibility to Oxidative Stress Exacerbates Cerebral Infarction that Follows Permanent Focal Cerebral Ischemia in Mutant Mice with Manganese Superoxide Dismutase Deficiency. J. Neurosci. 18 (1), 205-213. doi:10.1523/JNEUROSCI.18-01-00205.1998

Nybom, P., and Magnusson, K. E. (1996). Modulation of the Junctional Integrity by Low or High Concentrations of Cytochalasin B and Dihydrocytochalasin B Is Associated with Distinct Changes in F-Actin and ZO-1. Biosci. Rep. 16 (4), 313-326. doi:10.1007/BF01855015

Pemp, B., Polska, E., Karl, K., Lasta, M., Minichmayr, A., Garhofer, G., et al. (2010). Effects of Antioxidants (AREDS Medication) on Ocular Blood Flow and Endothelial Function in an Endotoxin-Induced Model of Oxidative Stress in Humans. Invest. Ophthalmol. Vis. Sci. 51 (1), 2-6. doi:10.1167/iovs.09-3888

Penfold, P. L., Provis, J. M., Furby, J. H., Gatenby, P. A., and Billson, F. A. (1990). Autoantibodies to Retinal Astrocytes Associated with Age-Related Macular Degeneration. Graefes Arch. Clin. Exp. Ophthalmol. 228 (3), 270-274. doi:10.1007/BF00920033

Pu, H., Tian, J., Andras, I. E., Hayashi, K., Flora, G., Hennig, B., et al. (2005). HIV-1 Tat Protein-Induced Alterations of ZO-1 Expression Are Mediated by RedoxRegulated ERK 1/2 Activation. J. Cereb. Blood Flow Metab. 25 (10), 1325-1335. doi:10.1038/sj.jcbfm. 9600125

Reed, J. C. (1995). Regulation of Apoptosis by Bcl-2 Family Proteins and its Role in Cancer and Chemoresistance. Curr. Opin. Oncol. 7 (6), 541-546. doi:10.1097/ 00001622-199511000-00012

Robison, W. G., Kuwabara, T., and Bieri, J. G. (1982). The Roles of Vitamin E and Unsaturated Fatty Acids in the Visual Process. Retina 2 (4), 263-281. doi:10.1097/00006982-198202040-00012

Rohrer, B., Bandyopadhyay, M., and Beeson, C. (2016). Reduced Metabolic Capacity in Aged Primary Retinal Pigment Epithelium (RPE) Is Correlated with Increased Susceptibility to Oxidative Stress. Adv. Exp. Med. Biol. 854, 793-798. doi:10.1007/978-3-319-17121-0_106

Romero-Vazquez, S., Llorens, V., Soler-Boronat, A., Figueras-Roca, M., Adan, A., and Molins, B. (2021). Interlink between Inflammation and Oxidative Stress in Age-Related Macular Degeneration: Role of Complement Factor $\mathrm{H}$. Biomedicines 309 (7), 763. doi:10.3390/biomedicines 9070763 
Sackett, C. S., and Schenning, S. (2002). The Age-Related Eye Disease Study: the Results of the Clinical Trial. Insight 27 (1), 5-7.

SanGiovanni, J. P., Chew, E. Y., Agrón, E., Clemons, T. E., Ferris, F. L., 3rd, Gensler, G., et al. (2008). The Relationship of Dietary $\omega$-3 Long-Chain Polyunsaturated Fatty Acid Intake with Incident Age-Related Macular DegenerationThe Relationship of Dietary Omega-3 Long-Chain Polyunsaturated Fatty Acid Intake with Incident Age-Related Macular Degeneration: AREDS Report No. 23. Arch. Ophthalmol. 126 (9), 1274-1279. doi:10.1001/ archopht.126.9.1274

Seddon, J. M., George, S., and Rosner, B. (2006). Cigarette Smoking, Fish Consumption, omega-3 Fatty Acid Intake, and Associations with AgeRelated Macular Degeneration: the US Twin Study of Age-Related Macular Degeneration. Arch. Ophthalmol. 124 (7), 995-1001. doi:10.1001/ archopht.124.7.995

Sen, C. K., Khanna, S., and Roy, S. (2006). Tocotrienols: Vitamin E Beyond Tocopherols. Life Sci. 78 (18), 2088-2098. doi:10.1016/j.lfs.2005.12.001

Szewczyk, K., Chojnacka, A., and Górnicka, M. (2021). Tocopherols and Tocotrienols-Bioactive Dietary Compounds; what Is Certain, what Is Doubt? Int. J. Mol. Sci. 22 (12), 6222. doi:10.3390/ijms22126222

Thomas, C. J., Mirza, R. G., and Gill, M. K. (2021). Age-Related Macular Degeneration. Med. Clin. North. Am. 105 (3), 473-491. doi:10.1016/ j.mcna.2021.01.003

Tisi, A., Feligioni, M., Passacantando, M., Ciancaglini, M., and Maccarone, R. (2021). The Impact of Oxidative Stress on Blood-Retinal Barrier Physiology in Age-Related Macular Degeneration. Cells 10 (1), 64. doi:10.3390/cells10010064

Toma, C., De Cillà, S., Palumbo, A., Garhwal, D. P., and Grossini, E. (2021). Oxidative and Nitrosative Stress in Age-Related Macular Degeneration: A Review of Their Role in Different Stages of Disease. Antioxidants (Basel) 10 (5), 653. doi:10.3390/antiox10050653

Tomany, S. C., Cruickshanks, K. J., Klein, R., Klein, B. E., and Knudtson, M. D. (2004). Sunlight and the 10-Year Incidence of Age-Related Maculopathy: the Beaver Dam Eye Study. Arch. Ophthalmol. 122 (5), 750-757. doi:10.1001/ archopht.122.5.750

Traber, M. G., and Atkinson, J. (2007). Vitamin E, Antioxidant and Nothing More. Free Radic. Biol. Med. 43 (1), 4-15. doi:10.1016/j.freeradbiomed.2007.03.024

Uchida, T., Nomura, S., Oda, H., and Ikeda, S. (2018). $\gamma$-Tocopherol Is Metabolized Faster Than a-Tocopherol in Young Japanese Women. J. Nutr. Sci. Vitaminol (Tokyo) 64 (6), 399-403. doi:10.3177/jnsv.64.399

Ungurianu, A., Zanfirescu, A., Nițulescu, G., and Margină, D. (2021). Vitamin E Beyond its Antioxidant Label. Antioxidants (Basel) 10 (5), 634. doi:10.3390/ antiox 10050634

Venugopal, R., and Jaiswal, A. K. (1998). Nrf2 and Nrf1 in Association with Jun Proteins Regulate Antioxidant Response Element-Mediated Expression and
Coordinated Induction of Genes Encoding Detoxifying Enzymes. Oncogene 17 (24), 3145-3156. doi:10.1038/sj.onc.1202237

Willems, S., Gellrich, L., Chaikuad, A., Kluge, S., Werz, O., Heering, J., et al. (2021). Endogenous Vitamin E Metabolites Mediate Allosteric PPAR $\gamma$ Activation with Unprecedented Co-Regulatory Interactions. Cel Chem. Biol. 28 (10), 1489-1500. doi:10.1016/j.chembiol.2021.04.019

Wong, W. L., Su, X., Li, X., Cheung, C. M., Klein, R., Cheng, C. Y., et al. (2014). Global Prevalence of Age-Related Macular Degeneration and Disease burden Projection for 2020 and 2040: A Systematic Review and MetaAnalysis. Lancet Glob. Health 2 (2), e106-16. doi:10.1016/S2214-109X(13) 70145-1

Yang, J. G., Zhou, C. J., Li, X. Y., Sun, P. R., Li, S. P., and Ren, B. C. (2015). Alteration of UCP2 and ZO-1 Expression in Trabecular Meshwork of Neovascular Glaucoma Patients. J. Glaucoma 24 (4), 291-296. doi:10.1097/ IJG.0b013e31829d9b91

Zhang, W., Ma, Y., Zhang, Y., Yang, J., He, G., and Chen, S. (2019). Photo-Oxidative Blue-Light Stimulation in Retinal Pigment Epithelium Cells Promotes Exosome Secretion and Increases the Activity of the NLRP3 Inflammasome. Curr. Eye Res. 44 (1), 67-75. doi:10.1080/02713683.2018.1518458

Zhong, Y., Zhang, B., Eum, S. Y., and Toborek, M. (2012). HIV-1 Tat Triggers Nuclear Localization of ZO-1 via Rho Signaling and cAMP Response ElementBinding Protein Activation. J. Neurosci. 32 (1), 143-150. doi:10.1523/ JNEUROSCI.4266-11.2012

Zingg, J. M. (2019). Vitamin E: Regulatory Role on Signal Transduction. IUBMB Life 71 (4), 456-478. doi:10.1002/iub.1986

Conflict of Interest: The authors declare that the research was conducted in the absence of any commercial or financial relationships that could be construed as a potential conflict of interest.

Publisher's Note: All claims expressed in this article are solely those of the authors and do not necessarily represent those of their affiliated organizations, or those of the publisher, the editors and the reviewers. Any product that may be evaluated in this article, or claim that may be made by its manufacturer, is not guaranteed or endorsed by the publisher.

Copyright $\odot 2022$ Duncan, Hurtado, Hall and Koulen. This is an open-access article distributed under the terms of the Creative Commons Attribution License (CC BY) The use, distribution or reproduction in other forums is permitted, provided the original author(s) and the copyright owner(s) are credited and that the original publication in this journal is cited, in accordance with accepted academic practice. No use, distribution or reproduction is permitted which does not comply with these terms. 